\title{
The Professional Quality of Life and Resiliency in Mental Health Professionals Working with Suicide in Crisis Care
}

\author{
William Bradley Little
}

Follow this and additional works at: https://researchrepository.wvu.edu/etd

\section{Recommended Citation}

Little, William Bradley, "The Professional Quality of Life and Resiliency in Mental Health Professionals Working with Suicide in Crisis Care" (2015). Graduate Theses, Dissertations, and Problem Reports. 6100. https://researchrepository.wvu.edu/etd/6100

This Dissertation is protected by copyright and/or related rights. It has been brought to you by the The Research Repository @ WVU with permission from the rights-holder(s). You are free to use this Dissertation in any way that is permitted by the copyright and related rights legislation that applies to your use. For other uses you must obtain permission from the rights-holder(s) directly, unless additional rights are indicated by a Creative Commons license in the record and/ or on the work itself. This Dissertation has been accepted for inclusion in WVU Graduate Theses, Dissertations, and Problem Reports collection by an authorized administrator of The Research Repository @ WVU.

For more information, please contact researchrepository@mail.wvu.edu. 
The Professional Quality of Life and Resiliency in Mental Health Professionals Working with Suicide in Crisis Care

\author{
William Bradley Little
}

Dissertation submitted to the College of Education and Human Services at West Virginia University in partial fulfillment of the requirements for the degree

\author{
Doctor of Philosophy \\ In \\ Counseling Psychology \\ Monica Leppma PhD, Chair \\ Jeffrey Daniels $\mathrm{PhD}$ \\ James Bartee PhD \\ Sam Zizzi PhD \\ Ed Jacobs PhD \\ Department of Counseling, Rehabilitation Counseling, and \\ Counseling Psychology
}

\author{
Morgantown, West Virginia \\ 2015
}

Keywords: Inpatient, Professional Quality of Life, Counseling, Suicide, and Resiliency Copyright 2015 William B. Little 


\section{ABSTRACT \\ The Professional Quality of Life and Resiliency in \\ Mental Health Professionals Working with Suicide in Crisis Care}

\section{William B. Little}

This study examined the professional quality of life (ProQOL) and resiliency among a sample of 85 active and licensed mental health professionals working in acute/crisis settings in the United States. Within the ProQOL construct exists the constructs of burnout, secondary-traumatic stress, and compassion satisfaction. It was hypothesized that impaired levels of resiliency, higher frequencies of contact (FOC) with clients admitted to care due to suicide, female gender, and fewer years of experience would be associated with increased burnout and secondary traumatic stress scores and decreased compassion satisfaction scores as measured by the Professional Quality of Life Scale Version 5. Multiple regression analyses indicated that FOC was not associated with burnout, secondary-traumatic stress, or compassion satisfaction. Contrary to previous findings, female gender and years of post-masters experience did not predict burnout, secondary traumatic stress, or compassion satisfaction within this sample. However, impaired resiliency level was found to be significantly associated with the onset of burnout, accounting for $27 \%$ of the variance. Furthermore, it was found that intact and healthy resiliency scores predicted the onset of compassion satisfaction, accounting for $24 \%$ of the variance. The results provided important empirical support of the relationship between resiliency, burnout, and compassion satisfaction. Limitations, strengths, conclusions, and future directions are discussed 


\section{Acknowledgements}

For my wife and family. They stuck with me, encouraged, and supported me in more ways than they can ever know. To them, I am forever grateful in the deepest and most sincere way. To Dr. Bartee and Dr. Daniels and other faculty in the department, thank you for taking a chance on a kid from Memphis and providing him with the challenge and support to grow. I think the ship has finally set sail. Thank you Dr. Leppma, you stepped in and took me on and never looked back. Your encouragement, support and guidance were invaluable. Finally, I want to thank Narayan Gold and my other cohort members. We completed this journey together and I wouldn't of have had it any other way. 


\section{Table of Contents}

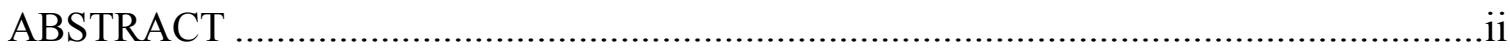

ACKNOWLEDGMENTS ............................................................................... iii

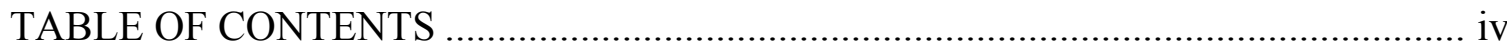

Chapter 1: INTRODUCTION AND LITERATURE REVIEW

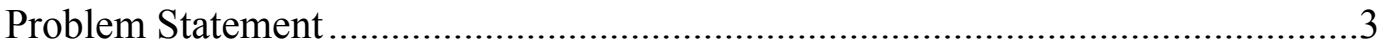

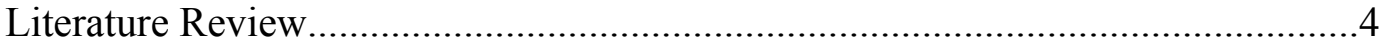

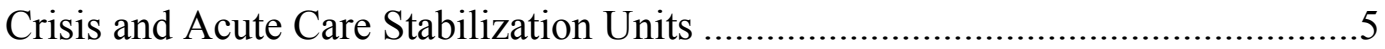

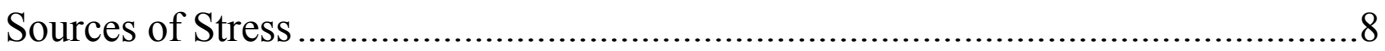

Clinician Vulnerability and Empathy .......................................................... 11

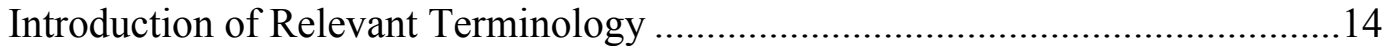

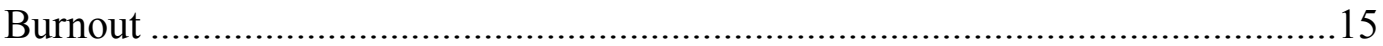

Risk and Protective Factors for Burnout....................................................... 17

Defining Compassion Fatigue and Secondary Traumatic Stress .........................18

Factors Influencing the Development of Compassion Fatigue...........................20

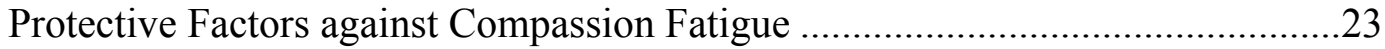

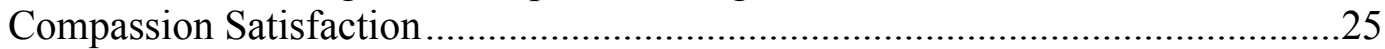

Professional Quality of Life (ProQOL) ........................................................26

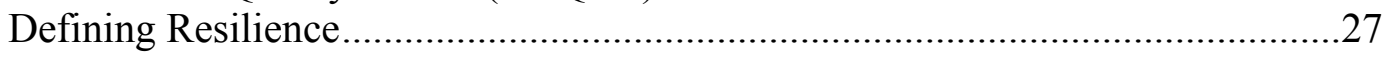

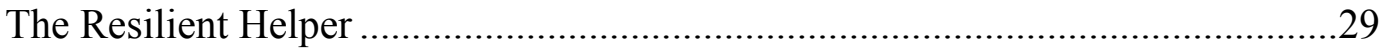

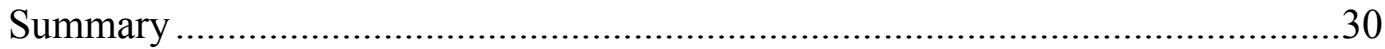

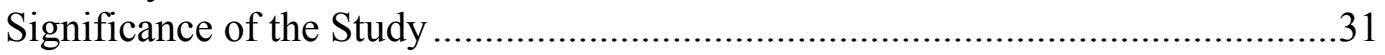

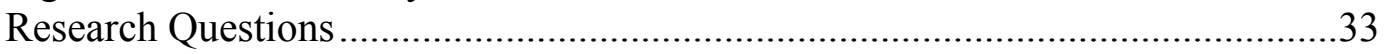

\section{Chapter 2: METHODOLOGY}

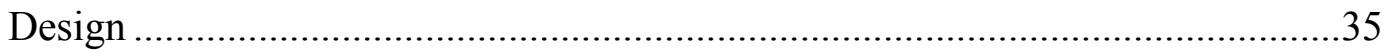

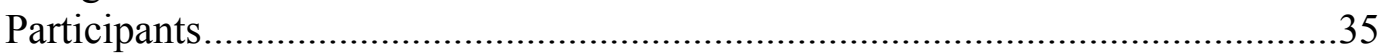

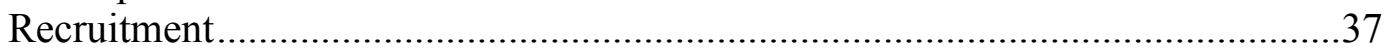

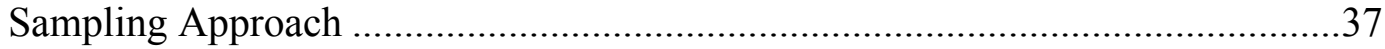

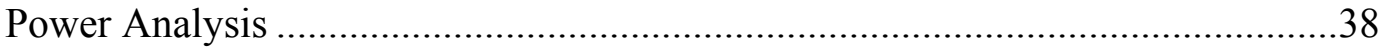

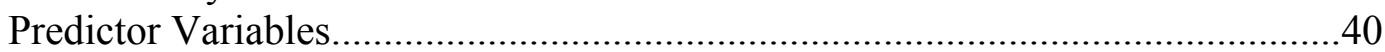

Dependent Variables (Measures) ................................................................... 41

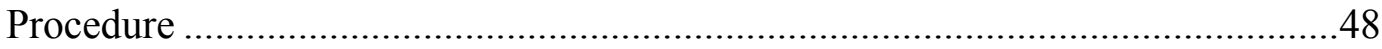

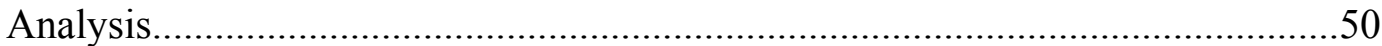

\section{Chapter 3: RESULTS}

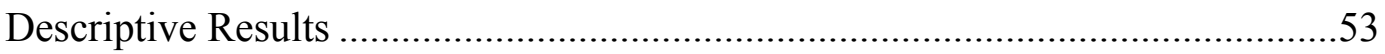

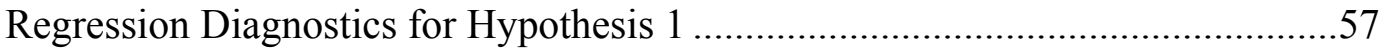

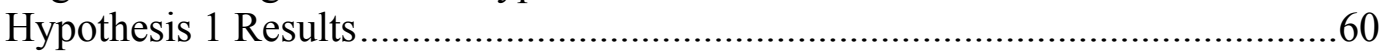




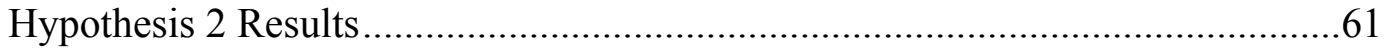

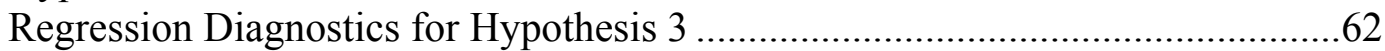

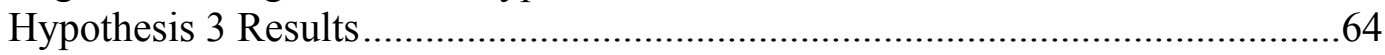

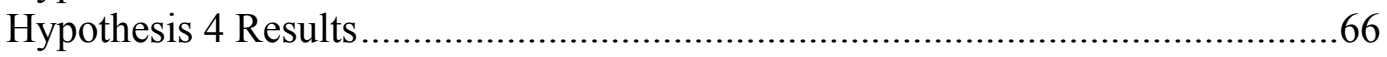

Chapter 4: DISCUSSION

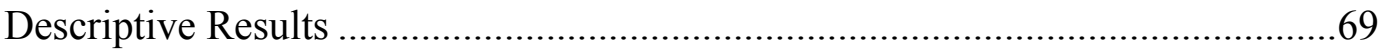

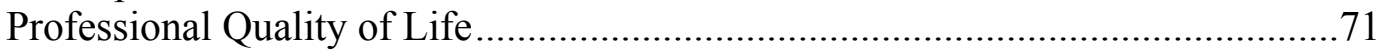

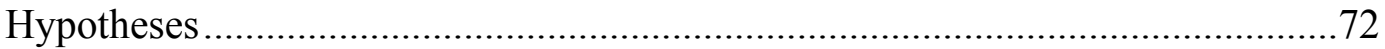

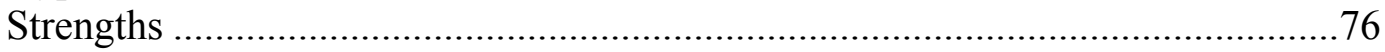

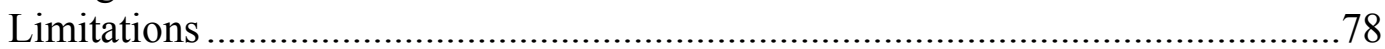

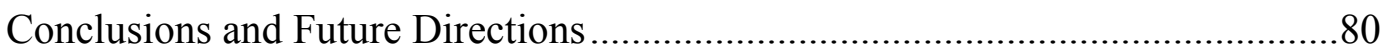

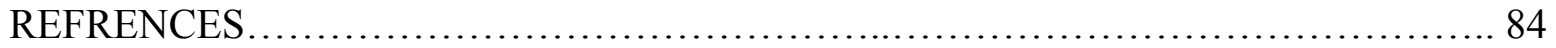

APPENDIX A. Professional Quality of Life Scale (ProQOL) Version 5 ……………......94

APPENDIX B. 14- Item Resiliency Scale .....................................................................95

APPENDIX C. Demographic Items …………………..........................................97

APPENDIX D. Recruitment Email Script _....................................................................98

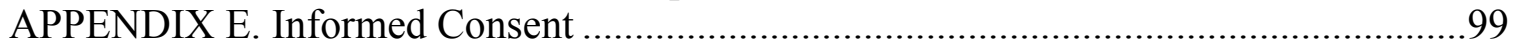




\section{The Professional Quality of Life and Resiliency in}

\section{Mental Health Professionals Working with Suicide in Crisis Care}

Exposures to suicidal presentations are commonplace for mental health professionals (MHPs) working in acute psychiatric and crisis stabilization environments, and this exposure represents a unique occupational hazard. Research findings have consistently shown that the processes associated with conducting counseling and psychotherapy with people experiencing high risk clinical presentations can lead to the development of conditions such as burnout, compassion fatigue, and secondary traumatic stress. These detrimental after-effects of helping have been shown to impair the efficacy of the therapeutic services provided while simultaneously impairing the general well-being of the treating clinician.

In the 1970 s, acute care units, then known as diversion units, were created as alternative time limited inpatient treatment placements for individuals demonstrating dangerous selfharming behaviors (Adams \& El-Mallakh, 2009). Today, diversion units are now referred to as Crisis Stabilization Units (CSU) and Acute Crisis Units (ACU) and these units are on the frontline in the treatment and prevention of suicide.

In 2007, the National Institute of Mental Health (NIMH) reported that suicide was the tenth leading cause of death in the United States; accounting for 34,598 lives (National Institute of Mental Health [NIMH], 2011). The American Foundation for Suicide Prevention (AFSP) estimated that on average 95 Americans take their lives on a daily basis, and 2,370 may attempt (American Association for Suicide Prevention [AASP], 2011). Additional estimates suggest that nearly $90 \%$ of people who die by suicide experienced a diagnosable psychological disorder at the time of their death (American Association of Suicidology [AAS], 2011). Affective, mood, cluster B personality disorders, psychotic, and substance abuse diagnoses appear to be commonly 
associated with elevated risks for death by suicide (Jacobs \& Brewer, 2004). In 2008, 376,306 people were admitted and treated in emergency departments (EDs) as a result of self-injurious behavior and 163,489 people were hospitalized (Centers for Disease Control and Prevention [CDC], 2013). Most likely, many of those thousands of people were referred and admitted to crisis stabilization and acute care psychiatric facilities where they received medication management and psychotherapy from licensed MHPs.

At some point in their careers, most mental health professionals (MHPs) will provide services to clients demonstrating suicidal behaviors. Some clinicians may even experience the death of a client due to suicide. According to McAdams and Foster (2000), 23.7\% of active licensed professional counselors (LPCs) reported that they had experienced a client suicide. Chemtob, Hamada, Bauer, Torigoe, and Kinney (1988) found among a sample of 365 licensed psychologists that $22 \%$ had experienced a client death due to suicide during their careers. Other evidence has shown that the likelihood of experiencing client suicide increases in certain clinical environments. For example, McAdams and Foster (2000) found within their study that one-third to one-half of psychiatric residents had experienced the death of a client as a result of suicide.

Perhaps it requires a special kind of clinician to thrive in the high stress, high pathology ACU/CSU clinical work environments. Within this fast paced and fluid sphere of care, treating clinicians are exposed to difficult clinical narratives and high-risk clinical situations. Lazarus and Folkman (1984) suggested that damaging aspects of stress emerge when the demands of a particular environment surpasses an individual's abilities to cope effectively. Further, recent research findings have indicated that job stress appears to be significantly related to the onset of professional burnout (e.g. Craig, \& Sprang, 2010; Fothergill, Edwards, \& Burnard, 2004; Lent \& Schwartz, 2012; Maslach; 1986, Raquepaw, \& Miller, 1989). Maslach (1986), a pioneer in 
literature concerning the topic of burnout found that emotional exhaustion, depersonalization, and reduced senses of personal efficacy and work accomplishment appeared to be the primary manifestations of the condition. Other findings have demonstrated that increased direct and vicarious exposures to stressful and traumatic situations in helping contexts appear to be significantly related to the onset of a condition known as compassion fatigue (Figley, 2002; Rothschild \& Rand, 2006).

\section{Problem Statement}

Through an exhaustive literature review, I found no studies that have explored how suicidal clinical presentations specifically impact the professional quality of life of practicing MHPs working in acute inpatient settings. Researchers have extensively examined emotional exhaustion, occupational stress, burnout, and compassion fatigue among populations of trauma counselors (e.g., Craig \& Sprang, 2010; Hummelvoll \& Severinsson, 2001; Lent \& Schwartz, 2012; Sørgaard, Ryan, Hill, \& Dawson, 2007; Sprang, Clark, \& Whitt-Woosely, 2007).

However, these studies did not focus specifically on the effects of working with suicidal clients.

Professionals who choose to work in inpatient crisis settings provide an important service to a population of clients that are in need of high quality and effective psychological care. However, this work can take a psychological toll on the clinician's general well-being and can negatively impact the efficacy of the services they provide (Craig \& Sprang, 2010). This study will assess how clinical work with suicide in the inpatient setting impacts the treating clinician's professional quality of life in both negative and positive ways. In addition, this study will represent an attempt to determine the adaptive functions of the resiliency construct among a specific population of mental health workers and how the construct is associated with professional quality of life. 


\section{Literature Review}

In recent years, a body of research has developed that has examined the circumstances thought to lead to the onset of the detrimental after effects of helping, specifically burnout (BO) and compassion fatigue (CF). For example, Lee, Lim, Yang, and Lee (2011) conducted a metaanalysis of 17 studies published in the United States concerning burnout among masters and doctoral level mental health practitioners (MHPs) employed in various work settings. Results demonstrated commonalities across all work settings. High levels of job-related stress (bureaucratic demands), over-involvement with clients, impaired perceptions of control, and inadequate professional identities appeared to be significantly correlated with the onset of BO (Lee et al., 2011). Additionally, increased levels of job stress and over-involvement with clients was found to be significantly associated with the onset of emotional exhaustion (Lee et al., 2011). Moreover, research findings have revealed that clinical interactions with difficult clients, more specifically, frontline exposure to trauma situations, appear to increase the likelihood of CF development (Cornille \& Meyers, 1999; Shah, Garland, \& Katz, 2007; Wee \& Myers, 2002). The effects of CF have been shown to produce symptom presentations similar to what is encountered in post-traumatic stress disorder (PTSD) (Jenkins \& Baird, 2002).

With these findings in mind, consider the ACU/CSU work environment. Inpatient MHPs regularly treat individuals who demonstrate complex psychopathologies and significant suicidal presentations. Pope and Tabachnick (1993) identified the prospect of client suicide to be one of the greatest fears helpers face. On a basic professional level, all clinicians are charged with the task of protecting their clients from themselves during times of crisis, and this unique aspect of the work likely contributes to already elevated levels of stress, emotional exhaustion, and feelings of pressure among CSU/ACU clinicians (Britton, Williams, \& Conner, 2008). 


\section{Crisis and Acute Care Stabilization Units}

Phillips et al. (2001) provided an outline of the basic functions of Acute/Crisis units and used the ten principles of assertive community treatments (ACT) as a guiding framework. According to Phillips and the ACT guidelines, the services in crisis and acute settings (a) are intended for individuals who present with severe mental illness or who are in severe emotional distress; (b) are provided directly by the ACT treatment teams (patients, psychiatrist, and other mental health providers); (c) are composed of treatment teams who work collaboratively in treatment interventions; (d) have high staff versus patient ratios (1:4); (e) provide a range of services (however, medical concerns are generally not addressed in these settings); (f) conduct psychotherapeutic interventions onsite rather than in a hospital or clinic; (g) do not provide time limits on receiving services (however, insurance coverage may dictate otherwise); (h) develop individualized treatments; (i) provide services on a 24 hours basis and (j) are proactive in monitoring patient progress (Phillips et al., 2001).

The American Academy of Child and Adolescent Psychiatry (AACAP, 2011) has recommended that an admission to an acute care psychiatric program, or CSU, is required when a person's safety is compromised due to psychological crisis or the possibility of harm to self or others. The same admission standards are applicable for adults. Today, these units represent the tip of the spear in the management and prevention of mental health related suicides, and MHPs working within these unique clinical environments are faced with the prospect of conducting counseling services in a high stress, high psychopathology, fast paced clinical environments where client safety is a primary concern (Hummelvoll \& Severinsson, 2001).

Acute/crisis therapists' primary clinical tasks are to foster psychological stabilization for admitted patients who are actively demonstrating dangerous behaviors or who have 
demonstrated dangerous behaviors in the recent past (Cunningham, 2003). Outcome studies have shown that a combination of psychosocial interventions (psychotherapy) and pharmacotherapy generally lead to the best results (Jacobs \& Brewer, 2004). However, research findings have also revealed that acute hospitalization may not be the most effective setting to conduct these services in some cases. For example, an admission to a psychiatric facility can create significant disruptions in the admitted client's psychosocial functioning (absenteeism from family, social supports, and employment) (Jacobs \& Brewer, 2004).

An admission to an acute facility represents an important first step in treatment for individuals demonstrating suicidal behaviors and more or less guarantees the safety of an admitted client (Jacobs \& Brewer, 2004). But, completed suicides do occur on these units. For example, it has been estimated that approximately 1,500 inpatient suicides occur in the United States each year within hospital settings, and a third of these occur when clients are identified as high-risk and placed under safety observation protocol (Jacobs \& Brewer, 2004). It appears that even though safety measures are taken to a high degree, inpatient clinicians are not immune to the risk of completed suicides among their clients.

Inpatient admissions also can shape the client's perceptions of psychological/psychiatric care and impact the success of later interventions. For instance, past research findings have shown that admission status (voluntary vs. involuntary) diagnosis, socioeconomic status, age, mental health history, gender, ethnicity, availability of social supports, and funding source can play crucial roles in treatment success (Balkin, 2006). However, further research is needed to better understand the interplay of these variables and how these variables influence clinical outcome (Balkin, 2006). 
Wallsten, Kjellin and Lindström (2006) examined 233 patients who were involuntarily or voluntarily admitted to crisis stabilization care in four Swedish specialty inpatient facilities. The researchers conducted clinical interviews within five days of admission and again at discharge or three weeks. The researchers tracked changes across these time frames through analysis of GAF scores, or the global assessment of functioning system provided within the DSM-IV (Wallsten et al., 2006). The results suggested that constructive and helpful interactions with clinical staff, low GAF scores on admission, and the presence of a mood disorder diagnosis appeared to be most predictive of improvement across time (Wallsten et al., 2006). The results also suggested that the coercive nature of involuntary commitments could be mitigated when clients felt they were being treated well by clinical staff and were informed about their treatment progress and discharge plans (Wallsten et al., 2006).

Through qualitative analysis, Clarke and Winsor (2010) attempted to describe the experiences of young adults admitted to acute inpatient care and their families' perceptions of the experience. The researchers found that admitted patients and their families largely felt relieved shortly after admission. However, these feelings did not seem to last. For example, many of the admitted clients reportedly developed negativistic perceptions of the treatment experience and feelings of loneliness and hopelessness were especially common among less chronically mentally ill clients (Clarke \& Winsor, 2010). Some clients even reported to feeling stigmatized as a result of their experiences on the unit (Clarke \& Winsor, 2010). Thus, inpatient MHPs are charged with effectively treating the presenting concern and also with managing the admitted client's overall treatment experience. Research has shown that this is an important duty as positive treatment experiences generally lead to better outcomes post-discharge. 
In summary, the complexities that MHPs face within the ACU/CSU work environments are many and unique when compared other clinical settings. MHPs are charged with a three-fold task. Through psychotherapeutic and psychotropic intervention they work to alleviate the emotional/psychological pain that triggered a preceding acute crisis which may have included a suicide attempt, active psychotic episode, self-harming behavior, or terroristic threatening. Secondly, MHPs work to manage the milieu and attempt to maintain a safe and therapeutic clinical atmosphere. Finally, MHPs work to develop discharge plans and treatment recommendations that utilize their client's psychosocial resources and connectedness to other available and less restrictive treatment options (Balkin, 2006; Jacobs \& Brewer, 2004). Further research is needed to assess how clinicians working in these complex and stressful work settings maintain clinical effectiveness and personal well-being.

\section{Sources of Stress}

Sprang, Clark, and Whitt-Woosley (2007) identified the importance of developing and maintaining caseloads that include variation in regards to the severity of clinical presentations. It is difficult for clinicians to work effectively and manage adequate self-care when they are faced with caseloads comprised entirely of difficult clients. However, this difficult proposition is a reality for many MHPs working in acute care settings simply as a result of the work environment. Crisis units do not turn away clients in need of services if beds are available, and these facilities must maintain high occupancy rates to remain financially viable (Balkin, 2006).

Sørgaard, Ryan, Hill and Dawson (2007) examined the various sources of stress for mental professionals based on clinical settings, and the researchers found that levels of emotional exhaustion appeared to vary. The authors reported that those employed in acute wards versus community placements appeared to demonstrate increased emotional strain (Sørgaard et al., 
2007). For example, community-based teams (outpatient settings) reported increased organizational problems, higher work demands, and minimized contact with colleagues. Yet, community-based practitioners also reported more fulfilling social relationships and increased feelings of control in their professional lives (Sørgaard et al., 2007). Clinicians working on acute units were comparatively more satisfied with the organizational structure of their work setting and experienced better access to colleagues during work hours. However, they reported an increased frequency of negative social environments outside of the work setting and decreased perceptions of in control within their professional trajectories (Sørgaard et al, 2007).

Hummelvoll and Severinsson (2001) investigated the ways in which MHP's cope with complexities of everyday work in psychiatric acute care settings. In this qualitative study, the researchers examined the coping styles of 16 professionals working in a 12-bed acute unit in the Sanderud psychiatric hospital located in Eastern Norway. The sample included 10 registered nurses and 6 participants acting in dual roles as therapists and hospital administrators. Results indicated that a primary source of stress was coping with uncertainty, which manifested in multiple domains: impaired professional identity, impaired physical milieu, diffuse boundaries between staff and clients, and feelings of stress related to perceptions of professional inadequacy (Hummelvoll \& Severinsson, 2001).

The possible consequence of a completed suicide for admitted patients to these facilities compounds the issues demonstrated by Hummelvoll and Severinsson (2001). Inpatient clinicians will likely face the intentional death of past clients, and are regularly exposed to extraordinary narratives replete with trauma and suffering (Jacobs \& Brewer, 2004). Research findings have shown that the prospect of a client suicide is a primary source of anxiety and fear for many 
therapists. For instance, Menninger (1991) found that treating clinicians experience astonishment, resentment, sadness, and guilt when they learn about client suicide.

Richards (2000) surveyed 100 outpatient psychotherapists in Britain. The sample was collected using a stratified random sampling technique and was drawn from members of UKCP National Register of Psychotherapists. Participants were asked to include biographical details such as years of experience and an estimate of the number of suicidal clients with whom they had worked throughout their career. Questionnaires were delivered in an open-ended format, and respondents were asked about the quality of the transference relationships with clients who demonstrated suicidal behavior and how this relationship impacted them, what supports were available, and what they had learned from the experience (Richards, 2000). According to Richards, 58 of 100 questionnaires were returned completed and $60.3 \%$ of the sample reported that they had worked with a suicidal client in the recent past. Six participants reported that they had experienced the death of a client due to suicide (10.3\%) and 29 participants (50\%) shared that they had worked with a client who had attempted (Richards, 2000). These findings demonstrated the negative psychological effects that can occur after experiencing a client's suicidal behaviors. For example, many therapists developed a disenfranchised view of the mental health system in general and directed their anger towards their clients and the referral source (Richards, 2000). Additionally, the processes associated with experiencing the death of a client due to suicide shook the confidence of many clinicians (Richards, 2000). One participant in particular shared their reaction to news of a client who completed her suicide attempt:

This is the month when it took place and I always remember the anniversary of it and this is 15 years ago. As you can tell I'm talking about it as if it happened very recently, the details don't need much dredging up. I think to be involved in 
something to that degree and then for something like this to happen, to me it's an indelible thing. I don't mean to say that I suffer from it now but I don't forget her. Because I think that everybody, family or therapist, whoever, has to mourn that sort of death. (Richards, 2000, pp. 335-336)

\section{Clinician Vulnerability and Empathy}

Carl Rogers provided applied psychology with an influential paradigm of change. Rogers believed the relationship formed between counselor and client to be central in promoting therapeutic change. Rogers (2007) core conditions of change are as follows: (a) the client and therapist are in a state of psychological contact, (b) the client, is in a state of incongruence, (c) the therapist is the congruent object in the relationship, (d) the therapist demonstrates unconditional positive regard for the client, (e) the therapist demonstrates empathy for the client, and (f) the therapist is able to communicate to the client his or her emphatic understanding and unconditional positive regard in constructive ways (Rogers, 2007).

Indeed, Rogers's work has influenced attempts to operationalize the therapeutic relationship. However, a clear understanding of how the clinician and client initially develop strong and change-promoting alliances remains elusive (O’Hara, 2012). For the last 20 years, researchers have attempted to understand why positive relationships formed in counseling sessions seem crucial in promoting therapeutic change (Flückiger, Del Re, Wampold, Symonds, \& Horvath, 2012). In fact, meta-analyses have shown that associations between strong therapeutic relationships and positive outcomes are robust, when most associations between specific counseling techniques and outcomes remain modest (Flückiger, et al., 2012). 
A relationship implies interactions between two or more systems and with interaction comes reciprocity. Sigmund Freud first took note of the reciprocal functions of psychotherapy and introduced the terms transference and countertransference to professional lexicon in the early 1900s. Today, most helpers acknowledge the fact, regardless of their grounding theoretical orientation, that the counseling process is a bidirectional process (Gelso \& Bhatia, 2012). Thus, if the therapeutic relationship is indeed the basic catalyst of therapeutic change, it is likely that the processes associated with maintaining it may contribute to the development of the detrimental after effects of helping. This may be especially true among helpers who commonly work with difficult case presentations such as trauma or suicide.

Figley (1995) suggested that empathic engagement, genuine care and concern, and strong working relationships are crucial to effective therapeutic work. However, Figley (1995) noted that the processes associated with maintaining effective therapeutic stances could also create a risk for the development of burnout and compassion fatigue. This is an acknowledgement of the potential hazards that may come with maintaining the core conditions, specifically empathy, within a bidirectional therapeutic relationship.

Interestingly, Figley's (1995) observations would also suggest that all clinicians might be vulnerable to develop burnout and compassion fatigue due to empathic engagement. However, we know not all clinicians do, even those who work with the most difficult clients. Relevant research findings have shown that the emergence of burnout and compassion fatigue appear to be higher in helpers who have personally experienced similar traumas to what they are treating and among helpers who are emotionally over-engaged with their clients (Figley, 1995). Furthermore, Bradley, Heim, and Westen (2005), provided some empirical support to the notion that unhealthy transference relationships can be based on the clinician's personality structure. These research 
findings lend some support to Carl Rogers's assumption that the therapist must be congruent in the relationship to promote change.

To date, there does not appear to be a solid objective and empirical answer to the question of whether or not a helper can be distanced yet sufficiently emotionally engaged with their clients in ways that wholly promote change and deflect negative reactions. Furthermore, what is considered to be emotional over-engagement, on the clinician's part, most likely varies on an individual basis. However, recent findings in medical research have shown that "the level of empathy correlates with burnout level negatively," which would suggest that increased levels of empathy might actually be protective against burnout (Wilczek-Rużyczka, 2011). It is unknown if this relationship exists among MHPs and if this relationship is mediated by the nature of the presenting clinical issue being treated.

Supervision, consultation, and continuing education have been shown to be effective in mitigating the negative effects of helping to some degree, and there appears to be solid evidence that suggests that there are important differences between cognitive and emotional empathy (Goodman, 2005). However, the connections between empathy and compassion fatigue have yet to be empirically researched and little is known about how and if empathy acts as a conduit to clinician vulnerability (Jenkins \& Baird, 2002). This connection is difficult to measure but seems highly face valid.

Elkins (2012) suggested that "we must acknowledge that for more than 100 years we have focused on the wrong factors in psychotherapy" and "we now need to correct this historical mistake by making major changes in research, training, and practice" (p. 453). According to Elkins (2012), the focus of research needs to be shifted away from attempts to determine the efficacy of certain techniques with focus more on how interpersonal processes between client 
and clinician lead to favorable clinical outcomes (Elkins, 2012). This is likely especially true in research endeavors that attempt to examine the toll of helping in general and in research that examines how specific clinical presentations impact the well-being and effectiveness of the treating clinician. Empathic engagement is a difficult skill to learn. Yet, it appears central to the counseling process and how empathy is expressed on an interpersonal level and internalized by helpers certainly varies on individual levels.

\section{Introduction of Relevant Terminology}

Professional burnout (BO) represented the initial nosology in a research stream that first examined the negative effects of helping. According to Leiter and Harvie (1996), BO describes the unique cost benefit relationship between helping and stress. Freudenberger (1985) proposed that BO emerges when a person's vitality and psychological resources to cope become exhausted as a result of both internal and sometimes external pressures. Additional terms originating from the $\mathrm{BO}$ construct are now commonly cited within the relevant literature. These terms include vicarious traumatization (VT), secondary traumatic stress (STS), and compassion fatigue (CF) (Rothschild \& Rand, 2006). Figley (1995) is credited with devising the term STS and defined it as "the natural and consequential behaviors and emotions resulting from knowing about a traumatizing event experienced by a significant other and the stress resulting from helping or wanting to help a traumatized or suffering person"' (p. 7).

According to Stamm (2010), researchers Figley, Stamm, and Pearlman have conducted over 50 scientific investigations surrounding the negative effects of helping and over 500 scholarly publications have been produced on the subject. A search within academic databases demonstrated the vast scope of interest in the constructs thought to be associated with the onset of the negative psychological and physical effects of helping. For example, using the term 
"burnout" within the Ebscohost online database produced, 853 peer reviewed journal articles between 1971 and 2013. A search using the term "compassion fatigue" resulted in 571 peerreviewed articles.

Even though these concepts appear very popular, among researchers Craig and Sprang (2010), the operational definitions of the constructs remain unclear. For example, the terms secondary traumatic stress, and vicarious traumatization are often used to describe similar conditions within the extant literature (Craig \& Sprang, 2010, p. 320). As such, Craig and Sprang (2010) reported that quantitative investigation of the STS and VT constructs have yet to show that the two conceptually distinct phenomena are actually divergent constructs.

Sabin-Farrell and Turpin (2003) conducted a review of empirical research on the CF, STS, and VT constructs and concluded that quantitative evidence supporting the existence of these conditions has been relatively inconsistent. However, many qualitative studies have shown substantial support for the existence of these phenomena among trauma workers (Sabin-Farrell \& Turpin, 2003). Conclusions like these suggest that there are helpers who experience negative consequences from working in the trauma field. However, the ingredients that comprise these experiences appear to be varied and have been historically difficult to quantify.

\section{Burnout}

Maslach (1982) defined burnout (BO) as "a syndrome of emotional exhaustion, depersonalization, and reduced personal accomplishment"' (Maslach, 1982, p. 3). Particular symptoms of the condition can be manifested in both the psychological and physiological domains. Psychological symptoms may include pessimism, negative social/interpersonal relationships, depressive like reactions, and apathetic emotional responses (Fothergill, Edwards, 
\& Burnard, 2004). Physiological symptoms can include a range of somatic complaints, decreased energy levels, and general feelings of malaise (Fothergill et al. 2004).

Maslach (1986) found that emotional exhaustion, depersonalization, and reduced sense of personal efficacy and accomplishment appear to be the three primary manifestations of the condition. Summarizing Maslach (1986), emotional exhaustion represents depletions in the psychic energy reserves needed to engage clients in a compassionate and caring way. Depersonalization is manifested in a lack of compassion emerging as frustration with the clinical presentations of the clients. Finally, feelings surrounding a lack of accomplishment and negativistic views of personal efficacy are thought to emerge when clinicians continually view minimal therapeutic gains and are overextended in their professional duties (Maslach, 1986).

Simply defined, BO represents the negative emotional and physical tolls that work in the helping profession can sometimes cause. However, the construct appears to be relatively holistic, and the factors associated with the probable onset of the condition can vary (high paperwork and other organizational demands) and are not necessarily solely related to effects of prolonged empathic engagement with difficult clinical presentations. For this study, BO will be included as a criterion variable and will represent one aspect of the professional quality of life construct as proposed by Stamm (2010). For the purpose of this project, I have adopted Stamm's (2010) definition of BO, which states:

Burnout is associated with feelings of hopelessness and difficulties in dealing with work or in doing your job effectively. These negative feelings usually have a gradual onset. They can reflect the feeling that your efforts make no difference, or they can be associated with a very high workload or a non-supportive work environment (Stamm, 2010, p. 13) 


\section{Risk and Protective Factors for Burnout}

Researchers have found that inexperienced clinicians appear to be at a significantly higher risk for burnout (BO) than their more experienced counterparts (Farber, 1990). However, age and experience are mutually exclusive phenomena. Therefore, it is difficult to pinpoint when the effects of age and experience distinguish from one another. However, Farber (1990) suggested that younger clinicians appear to be at a higher risk of $\mathrm{BO}$ because they have yet to learn to separate their personal and professional lives, are more prone to experience greater levels of negative countertransference, and may internalize negative client projections on their newly formed professional competencies and identities.

Lent and Schwartz (2012) investigated relationships between BO and clinical work setting, demographic characteristics, and personality factors among a national sample of licensed professional counselors (LPCs) $(n=340)$. The researchers found significant differences in the degree of $\mathrm{BO}$ between work settings. However, the results were contrary to what might be expected. Community mental health outpatient counselors demonstrated significantly higher levels of BO when compared to inpatient and private practice counselors (Lent \& Schwartz, 2012). No clear patterns emerged when considering demographic factors as significant interactions were found in relation to gender, race, and years of experience (Lent \& Schwartz, 2012). In fact, the researchers found that high levels of neuroticism to be strongest predictor of $\mathrm{BO}$ and the level of neuroticism significantly predicted the severity of BO in three domains first identified by Maslach (1986) (e.g. emotional exhaustion, depersonalization, and personal accomplishment). These results were consistent across all clinical settings included in the Lent and Schwartz 2012 study. 
Raquepaw and Miller (1989) examined the development of BO when considering caseload size. The authors found that outpatient clinicians who favored smaller caseloads scored in more disrupted ranges on the Emotional Exhaustion subscale of the Maslach Burnout Inventory (MBI;1986). The MBI is a measure with strong psychometric properties commonly used to assess multiple domains of professional burnout among those working in human service, education, business, and government professions (Maslach \& Jackson, 1986). Raquepaw and Miller (1989) also found that clinicians who felt overwhelmed scored higher on the Depersonalization subscale of the MBI. These findings suggested that perceptions of efficacy and effective coping appear to be important protective factors in regards to the prevention of $\mathrm{BO}$ (Raquepaw \& Miller, 1989).

\section{Defining Compassion Fatigue and Secondary Traumatic Stress}

Compassion fatigue $(\mathrm{CF})$ refers to the negative emotional and physical effects that MHPs sometimes experience secondary to the chronic use of empathy when treating clients in turmoil (Figley, 2002; Rothschild \& Rand, 2006). Figley (2002) has suggested that empathic engagement may be the primary vehicle of traumatic stress from client to therapist. It is important to note that within the literature, the terms secondary traumatic stress (STS) and CF are commonly used interchangeably and this can cause some confusion at times. However, compassion fatigue is now the favored phraseology as the term denotes fewer negative connotations (Craig \& Sprang, 2010).

Stamm (2010) has conceptualized STS as a distinct aspect of the CF construct. According to Stamm, STS develops as a result of regular exposures to client narratives that carry traumatic experiences. The negative effects of STS may include "fear, sleep difficulties, intrusive images, or avoiding reminders of the person's traumatic experiences" (Stamm, 2010, p. 13). 
Jenkins and Baird (2002) provided empirical evidence for the differentiation of the constructs of vicarious traumatization (VT) and STS/CF. The researchers concluded that vicarious traumatization may represent negative cognitive shifts while STS (CF) represents negativistic shifts in more affectual and interpersonal areas of functioning (Jenkins \& Baird, 2002).

Compassion fatigue and secondary traumatic stress have also been conceptualized as syndromes similar to Post Traumatic Stress Disorder (PTSD) as included in the DSM-5 (American Psychiatric Association, 2013). However, it is important to note that compassion fatigue and secondary traumatic stress are not diagnosable psychological conditions based on current psychiatric diagnostic systems. Stamm (2010) believes that compassion fatigue is best understood when considering the components of the construct in both isolation and interaction, as the CF construct is comprised of two distinct parts. The first aspect of construct produces symptoms that mirror the symptoms found in burnout. The second aspect of the construct consists of symptoms produced by secondary traumatic stress exposures (Stamm, 2010). For this research, compassion fatigue was defined as the collective effects of both burnout and secondary traumatic stress.

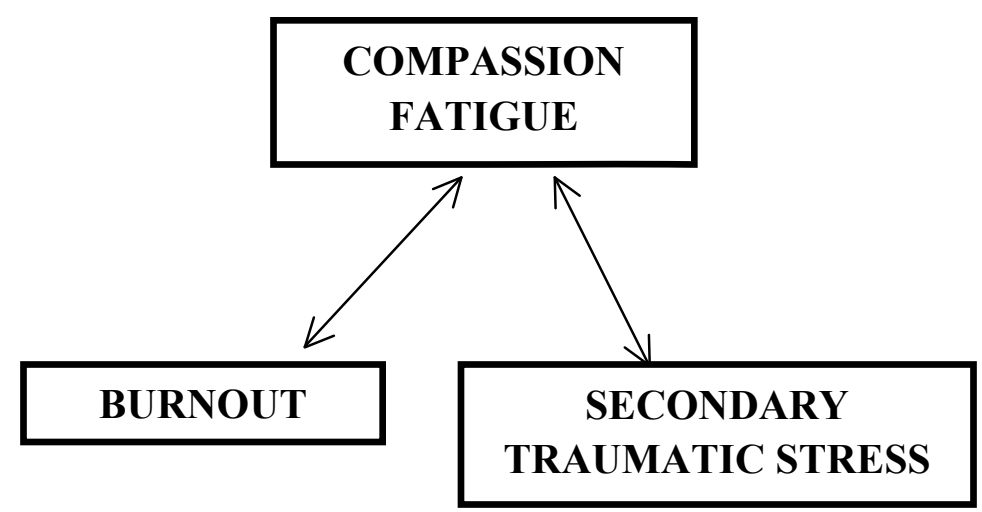

See Figure 1.1 above. Model of Compassion Fatigue (Stamm, 2010) 


\section{Factors Influencing the Development of Compassion Fatigue}

Researchers findings have continually demonstrated that MHPs working with difficult clients are prone to the development of compassion fatigue (CF), and there is epidemiological support for the emergence of compassion fatigue among those working on the frontlines treating trauma in both mental health and non-related mental health fields (e.g., Cornille \& Meyers, 1999; Shah et al., 2007; Wee \& Myers, 2002).

Sprang, Clark and Whitt-Woosley (2007) examined the relationship between compassion fatigue $(\mathrm{CF})$, compassion satisfaction $(\mathrm{CS})$, and burnout $(\mathrm{BO})$ in relation to provider and setting characteristics among a sample of 1,121 mental health providers operating in rural southern states of the United States. Participants included licensed and active psychologists, psychiatrists, social workers, marriage and family therapists, professional counselors, and drug and alcohol counselors. The average age of participants was 45.22 years ranging from 23 to 81 years. Most participants held a master's degree and had 13.92 years of experience $(S D=9.54)$ (Sprang et al., 2007). When divided by locale, $35.8 \%$ worked in community mental health settings, $13.6 \%$ in public agencies, $29.6 \%$ in private practice, $6.2 \%$ in inpatient facilities, $4.9 \%$ in other public agencies and $9.9 \%$ in other settings. In terms of gender, $30.4 \%$ of the participants were male and 69.6\% were female. Furthermore, all participants were asked to self-identify whether or not they had specific training in trauma work (Sprang, Clark, \& Whitt-Woosley, 2007).

Participants in the Sprang et al. (2007) study completed the Professional Quality of Life Scale Version 4 (ProQOL) which is a 30-item self-report measure used to assess for the potential risk of the development for compassion fatigue (CF). High scores on the CF subscale, which includes 10 items, suggests that respondents are at high risk for the development of CF. The results of the Sprang et al. (2007) study demonstrated that female gender appeared to be 
associated with higher levels of CF. However, to make the conclusion that female gender is a risk factor for the development of compassion fatigue among mental health workers may be premature as this sample was overrepresented with female participants. Indeed, this mirrors the current demographic makeup of mental health professionals in the United States so some conclusions can be made, yet, an overrepresentation effect may have skewed the results (Sprang et al., 2007).

Younger and less experienced clinicians who work with trauma and experience occupational stressors appear to be at increased levels of risk for the development of compassion fatigue (Badger, Royse, \& Craig, 2008; Craig \& Sprang, 2010, Ghahramanlou \& Brodbeck, 2000). Findings have also shown that practitioners who have personally experienced anxiety and mood disorders or have experienced a personal trauma (particularly child abuse and neglect) are at greater risks for developing the negative effects of helping in the form of compassion fatigue (Lerias \& Byre, 2003).

In addition, occupational title appears to be a relevant variable in the development of compassion fatigue. Sprang et al. (2007) conducted a MANOVA on CS, CF, and burnout using the ProQOL Version 4 instrument. Within their design, the researchers controlled for highest educational degree (bachelor's vs. master's vs. PhD vs. MD) (Sprang, et al., 2007) and the results showed that psychiatrists demonstrated higher levels of CF when compared to nonmedical professionals (Sprang et al., 2007). Post hoc analyses revealed that MDs demonstrated greater CF scores than LCSWs, psychologists, and LSWs (Sprang et al., 2007). No other significant differences or relationships where found in scores among non-medical mental health providers. These finding are not entirely surprising in that psychiatrists have a high frequency of contact with individuals experiencing significant forms of mental illness and are often the key 
decision-makers in both community mental health and inpatient hospital settings (Sprang et al., 2007).

In terms of clinical setting, Sprang et al. (2007) demonstrated variations in scores of compassion satisfaction, compassion fatigue, and burnout. Scheffe's post hoc analysis revealed that inpatient professionals produced significantly higher burnout scores than private practice professionals $(p=.05)$. Yet, $13 \%$ of all clinicians scored in the high risk ranges for CF and BO. These results demonstrated two interesting findings. One, inpatient clinicians may be more prone to burnout and two, a great number of MHPs in general score in impaired ranges of burnout regardless of setting. These results provide important support for ongoing investigations of how certain clinical environments impact burnout scores in general. Additionally, regression analysis demonstrated that "female gender, young age, a higher educational degree, less clinical experience, and a higher percentage of clients with PTSD predicted higher levels of CF and burnout" (Sprang et al., 2007, p. 271). In summary, research findings suggest that younger female inpatient clinicians working with trauma may be the population of helpers most prone to develop BO and CF.

Utilizing the levels of evidence research methodology, Baird and Kracen (2006) assessed the findings of studies published from 1994 to 2003 concerning topics of vicarious traumatization and secondary traumatic stress. Both peer reviewed publications and doctoral dissertations concerning the topics were included in the analyses (Baird \& Kracen, 2006). Among other findings, the researchers found that high exposure to difficult presentations such as PTSD, appeared to increase the risk for the development of STS (Baird \& Kracen, 2006, p. 184). The "Level-of-evidence" for this finding was "persuasive" (Baird \& Kracen, 2006, p. 184). 
Findings such as found in the Baird and Kracen (2006) study underscore the importance of developing research studies that consider dose-effect phenomena.

Badger, Royse and Craig (2008) examined the predictive function of empathy, emotional separation, occupational stress and social support in regards to the development of secondary traumatic stress among hospital social workers. The study included a sample of 121 trauma center social workers. Participants were largely female master's level clinicians with 15.8 years of experience on average (Badger et al., 2008). The results demonstrated that emotional separation and occupational stress appeared to be the strongest predictors of secondary traumatic stress, explaining $49 \%$ of the measured variance (Badger et al., 2008).

\section{Protective Factors Against Compassion Fatigue}

Not all who are engaged in trauma work develop the adverse psychological effects of helping, and research has identified certain protective factors. For example, Rich (1997) identified regular access to clinical supervision as a protective factor for professionals working with sexual abusers. Follette, Polusny, and Millbeck (1994) examined the phenomenon of secondary traumatization and assessed the psychological impact on professionals when providing services to sexual abuse victims. The study included a sample of 558 mental health and law enforcement professionals from a western state in the United States. The mental health sample included 164 licensed psychologists and 307 marriage and family therapists (MFT). Law enforcement group of participants included 87 trained investigative police officers. Similar to previous studies, the results showed personal-trauma history to be a predictive factor for the onset of secondary traumatic stress (compassion fatigue) (Follete et al., 1994). The researchers also found that education and trauma specific training appeared beneficial in mitigating $\mathrm{CF}$ development and reported that $96 \%$ of mental health professionals and $93 \%$ of law enforcement 
officers who educated themselves about sexual abuse demonstrated more effective modes of coping when working with difficult sexual abuse cases (Follette et al., 1994).

Specific training in trauma, adherence to empirically supported treatments, and increased age appear to be three protective factors among trauma therapists (Craig \& Sprang, 2010). For instance, Craig and Sprang (2010) examined a sample of clinical psychologists and clinical social workers $(n=542)$ who worked with trauma. The authors reported that $47 \%$ of the sample held doctoral degrees and $52 \%$ held master's degree. In addition, $62 \%$ of the sample reported that they had received specialized training in treating trauma (Craig \& Sprang, 2010).

Craig and Sprang (2010) were primarily concerned with whether or not an adherence to evidence-based practices and trauma training mitigated the development of $\mathrm{CF}$ and $\mathrm{BO}$. Implementing hierarchical regression, the results indicated that having no previous trauma training, being exposed to a high number of individuals presenting with PTSD on a caseload, working in the inpatient sphere of care and not adhering to evidence-based practices increased the likely emergence of burnout (Craig \& Sprang, 2010). In terms of the development of CF Craig and Sprang (2010) reported that practitioners who worked with caseloads containing a high percentage of PTSD clients and those who did not adhere to evidence-based models of treatment were found to be especially prone to develop CF.

Clinician experience has also been shown to be a protective factor. Cunningham (2003) developed a study to assess the relationships between human-induced trauma (sexual abuse) versus naturally occurring trauma (cancer) and how the work with these two differing forms of trauma affected clinician worldview. Results showed that clinicians who worked with clients who presented with sexual abuse traumas demonstrated higher levels of vicarious traumatization when compared to clinicians working with clients with cancer (Cunningham, 2003). However, 
years of experience and personal trauma experience were identified as confounding variables (Cunningham, 2003).

The results of the Cunningham (2003) study demonstrated a significant negative correlation $(r=-.23, p=.001)$ between number of years in a trauma specialty (sexual abuse vs. trauma) and a negative total score on the Traumatic Stress Institute Belief Scale (TSIBSRevision L: Pearlman, 1996). Additionally, the number of years in specialty also correlated negatively with subscales of self-safety on the TSIBS $(r=.17, p=.01)$ and other-esteem $(r=-$ $.14, p=.04)$ (Cunningham, 2003). In summary, these findings indicated that the clinicians who had greater years of experience and worked with forms of trauma originating from naturally occurring events demonstrated fewer disruptions in their cognitive schemas (Cunningham, 2003). This finding is especially relevant to the current study in that suicide is a human induced trauma.

\section{Compassion Satisfaction}

Compassion satisfaction (CS) refers to positive feelings and the pleasures derived from helping others and society through vocational endeavors. It also represents the abilities to feel positive about the work environment and colleagues (Stamm, 2010). Stamm (2010) defines CS as:

The pleasure you derive from being able to do your work well. For example, you may feel like it is a pleasure to help others through your work. You may feel positively about your colleagues or your ability to contribute to the work setting or even the greater good of society (p.12) 
This definition and explanation will be adopted for this study. The CS construct was developed to specifically apply to those in the helping the professions and various factors have been identified to increase the likelihood of the occurrence of CS.

Linley and Joseph (2007) found that female therapists who received personal therapy and supervision when engaged in trauma work tended to show favorable outcomes in terms of their professional quality of life (high CS). Rossi et al. (2012) identified that CS development appears more likely among practitioners who demonstrate low levels of personal distress. These findings lend support to the notion that resiliency and CS may be significantly intertwined as it may be possible that helpers who are able to manage their affairs outside of sessions are likely able manage work related distress effectively as well. As mentioned previously, supervision, trauma training, education, and adherence to empirically supported treatments all function as protective factors among trauma workers (e.g., Follette, Polusny, \& Millbeck Rich, 1997; Sprang et al., 2007)

\section{Professional Quality of Life (ProQOL)}

A clinician's professional quality of life (ProQOL) represents the interactions between the constructs of compassion fatigue/secondary traumatic stress (CF/STS), burnout (BO), and compassion satisfaction (CS) (Stamm, 2010). It is believed that clinicians who are able to maintain a more favorable ProQOL are more effective helpers when compared to clinicians who are unable to adequately manage personal and occupational concerns (Lawson, Venart, Hazier, \& Kottler, 2007). Conceptually, the ProQOL construct represents interactions between both the negative and positive influences that can impact a clinician's work and efficacy. In many ways, this construct also represents a clinician wellness model. 
In terms of present the study, the ProQOL will be defined as the interactions between $\mathrm{BO}, \mathrm{STS} / \mathrm{CF}$, and CS. To illustrate these interactions, it is believed that individuals who demonstrate higher levels of CS when compared to BO and CF will tend to show a more favorable ProQOL and will inversely be better-equipped helpers (Stamm, 2010). However, significant questions remain as to how CS develops and is maintained. It is now known that certain factors can mediate the development of BO and CF but it is currently unknown how resiliency acts within these relationships.

\section{Defining Resilience}

Research concerning the construct of resilience began in the 1970s as researchers were initially interested in developing understandings of why some children thrived in the face of adversities whereas others did not. Over the last 40 years, the scope of resiliency research has broadened beyond child-aged populations and now represents a common construct found in much of the relevant literature (Tugade, Fredickson, \& Barett, 2004). Early operational definitions of the construct defined resiliency as the "dynamic capacity of an individual to modify his/her modal level of ego-control, in either direction, as a function of the demand characteristics of the environmental context” (Block \& Block, 1980 p.48).

Later in the literature, the definition of resilience changed in scope focusing more on personality factors. For example, Wagnild and Young (1990) suggested that resiliency may be a personality characteristic that functions to mitigate the negative effects of stress, promoting adaptation. A more recent definition provided by Tugade et al. (2004) suggested that resiliency is best defined as the ability to bounce back from negative events through use of positive emotions to cope. 
Ong, Bergeman, and Boker (2009) highlighted how the operational definition of the resiliency construct has adapted as research in the area has promulgated. However, one conceptual idea has remained and this idea is that without adversity or turmoil, resiliency could not be demonstrated (Ong, Bergeman, \& Boker, 2009). Luthar (2006) proposed that the core components of resiliency are related to the abilities to be adaptive and sustainable even in the face of exposure to difficult circumstances and environments in which others would be unable to thrive.

The operational definition of resiliency has also vacillated between state versus trait explanations and definitions of the resiliency construct have received a considerable amount of speculation in recent years. This debate has primarily centered on whether or not resiliency is inherited or fixed at some point during the developmental course. For instance, it is still unknown if resiliency is a personality trait or emerges when a person is confronted with adversity.

This study will represent an attempt to determine the adaptive functions of resiliency among a specific population of mental health workers and how the construct relates to the professional quality of life construct. Rutter (2007) suggested that resilience cannot be measured and thus cannot exist without the presence of adversity. Therefore, resiliency is viewed in this study as a process rather than outcome-based phenomenon. According to Kolar (2011), research that adopts a process view of the resiliency construct allows for a focus on the holistic interplay of factors. Moreover, Kolar (2011) states, "a process-based understanding facilitates the evaluation of resilience as a shared responsibility between individuals, their families, and the formal social system rather than as an individual burden" (Kolar, p. 425). In adopting the theoretical position of resiliency as a process related construct, I believe this research will be 
well-equipped to make conclusions about the complex interplay between therapeutic work with suicidal clients in the unique and distinctive occupational atmosphere that are crisis stabilization units.

\section{The Resilient Helper}

A great number of MHPs enter the profession due to an altruistic drive to help. Murphy and Halgin (1995) examined the source of this drive. Murphy and Halgin (1995) compared the motivations of professionals within various subspecialties of psychology and concluded that helping professionals sometimes reported increased frequencies of developmental stressors when compared to those in other non-healthcare related professions. Thus, these findings suggest that helpers are driven by their own past experiences, to learn to understand themselves on deeper levels or to prevent what happened to them from happening to others.

Bride (2004) reviewed 17 quantitative studies assessing the effects of delivering "psychosocial services" to traumatized populations. Within these studies, the most commonly studied variables included age, gender, exposure levels, training, occupation, personal trauma history, and client trauma symptoms. Bride (2004) reported mixed results, and no clear patterns were found in regard to demographic factors, exposure levels, and the type of trauma clients. However, there was some consistency in that a clinician's "personal trauma history, particularly in childhood" [was a] "significant risk factor" (p. 42) for the development of adverse psychological consequences of helping.

Edward (2005) explored the "phenomenon of resilience" among Australian crisis care mental health clinicians employed in a high stress, fast-paced, and dynamic clinical setting (p. 142). The study included six participants selected from a Melbourne, Australia metropolitan mental health organization. Five of the six participants were female, and participants represented 
professionals working in nursing, allied health, and medicine. Data were reportedly analyzed using the seven-step information analysis approach developed by Colaizzi. In this qualitative investigation, clinician resiliency emerged and was maintained through five themes, which included "the team is a protective veneer to the stress of the work, sense of self; faith and hope; having insight; and looking after yourself' (Edward, 2005, p. 142). According to Edward (2005):

Despite the unrelenting and demanding nature of psychiatric crisis care work, many of my professional colleagues who entered this field 10-20 years ago have not succumbed to the pressure of the workplace but rather, have continued to remain enthusiastic, empathic and skilled in their clinical approach to care, while others became burnt-out (p.143)

\section{Summary}

Throughout this review, I have described the professional activities of MHPs working in the acute/crisis stabilization settings and defined the aspects of the professional quality of life construct. I have also illustrated the many occupational hazards and sources of stress associated with providing psychotherapeutic services to clients admitted to crisis care due to suicidal ideations and behaviors. Furthermore, I discussed the construct of resiliency and how the construct may act as a buffer against the development of the adverse effects of helping in practitioners operating within this unique vocational sphere.

Research findings have continually shown that MHPs working with difficult clinical case materials are prone to the development of compassion fatigue (CF) and burnout (BO) (e.g., Cornille \& Meyers, 1999; Shah et al., 2007; Wee \& Myers, 2002). Key findings suggest that inpatient practitioners demonstrate significantly higher levels of BO scores when compared to 
private practice professionals (Sprang et al., 2007). Other findings have indicated that a great number of practitioners in general experience CF (Sprang, et al., 2007).

Certain demographic factors have been identified in that appear to be associated with the onset of BO and CF (e.g., female gender, younger age, educational degree, and fewer years of clinical experience) (Badger et al., 2008; Ghahramanlou \& Brodbeck, 2000; Sprang et al., 2007). Other results have indicated that having no previous trauma training, being exposed to a high number of individuals presenting with PTSD on a caseload, working in the inpatient sphere of care and not adhering to evidence-based practices increases the likely emergence of BO (Craig \& Sprang, 2010). Trauma specific training, supervision and consultation have been continually identified as serving important protective and preventative functions against the development of the adverse consequences of helping (Craig \& Sprang, 2010; Sprang et al., 2007).

\section{Significance of the Study}

The studies included in this review provide the foundation for my research questions. It seems the predictive line for the development of secondary traumatic stress (STS), compassion fatigue (CF), and burnout (BO) has been somewhat well established by research examining trauma workers in general. However, I am unaware of empirical investigations that have assessed for the development of STS, BO, and compassion satisfaction (CS) among inpatient MHPs when considering the impact of regular exposure to suicidal presentations.

In this dissertation I will examine the construct known as the professional quality of life (ProQOL) among MHPs working with adult suicidal clients in crisis settings. Within the ProQOL construct exists the conditions known as STS, CS, and BO. In the current study, these conditions will be included as the primary criterion variables as measured by the Professional 
Quality of Life Scale Version-5 (ProQOL). From a theoretical standpoint, it is believed that BO and STS contribute to a condition known as CF (Stamm, 2010).

Cunningham (2003) recommended that future studies of vicarious traumatization or CF should include investigation of clinician personality factors that may serve as either agonist or antagonist to the development of the negative effects of helping. In keeping with this concept, clinician resiliency will be measured among selected MHPs and included as a predictor variable within regression analyses. It is hypothesized that clinician resiliency may prove to be an important factor that needs consideration when attempting to develop a holistic understanding of the already known risk factors. For example, it may be possible that intact resiliency enable some clinicians to thrive on both personal and professional levels when working in fast paced, high-risk, high psychopathology clinical environments. To measure resiliency levels among selected clinicians, the 14-Item Resilience Scale (RS-14; Wagnild, \& Young, 2011) will be administered.

To date, there has not been a quantitative investigation of the professional quality of life construct among MHPs specifically engaged in clinical work with suicidal clients in the crisis stabilization setting. Past research investigating the constructs that comprise the ProQOL have focused on developing understandings of the detrimental effects of helping in general (e.g., Farber, 1990; Figley, 2002; Maslach, 1982; Freudenberger, 1974; Rothschild, \& Rand, 2006), and few studies have specifically examined how CS emerges (e.g., Stamm, 2002). I hypothesize that high levels of clinician resiliency may be specifically related to the onset of CS and may operate in protective role against the potential emergences of BO and STS among both trauma workers in general and among those who work with suicide in crisis settings. 
Past research findings have demonstrated that the development of STS/CF and BO are related to prolonged exposure to clinical situations that are stressful and potentially vicariously traumatizing (Cornille \& Meyers, 1999; Rich, 1997; Shah et al., 2007; Wee \& Myers, 2002). To assess for the role that vicarious traumatization may play in the development of maladaptive levels of STS and BO among this population of professionals, the frequency of contact with clients admitted to crisis stabilization care as measured by MHP caseload self-report will be included as a significant variable of interest.

The results of this proposed research will forward the body of literature so more precise understandings of the detrimental psychological consequences of clinical work with suicidal clients in the crisis stabilization atmosphere may develop. One aim of this study will be to acquire a general understanding of the prevalence and severity of STS and BO among an active sample of MHPs working with suicide. Furthermore, this study will hopefully provide evidence in regards to how clinician resiliency and varying levels of exposure to suicidal clients impact the development of CS. I have developed four research questions to address within this study.

Question 1: Will greater frequencies of contact with suicidal clients and low levels of clinician resiliency predict impaired levels of clinician burnout (as measured by the ProQOL Version 5) among MHPs working in crisis/acute inpatient settings?

Question 2: Will greater frequencies of contact with suicidal clients and low levels of clinician resiliency predict impaired levels of secondary traumatic stress (as measured by the ProQOL Version 5) among MHPs working in crisis/acute inpatient settings?

Question 3: Will fewer frequencies of contact with suicidal clients and high levels of clinician resiliency predict favorable scores in compassion satisfaction (as measured by the ProQOL Version 5) among MHPs working in crisis/acute inpatient settings? 
Question 4: Will female gender, fewer years of post-master's experience, and high frequencies of contact with clients admitted to care due to suicidal behaviors predict decreased scores on the Compassion Satisfaction subscale as measured by the ProQOL Version-5? 


\section{Chapter 2}

\section{Method}

This dissertation attempted to quantitatively describe the professional quality of life (ProQOL) of mental health practitioners (MHPs) who regularly work with adult suicidal clients in the crisis stabilization setting. Within the ProQOL construct three conditions exist known as secondary traumatic stress (STS), burnout (BO), and compassion satisfaction (CS). These constructs were included as the primary criterion variables as measured by the Professional Quality of Life Scale Version 5. Additionally, clinician resiliency was included as a predictor variable to determine how and if clinician resiliency is associated with the onset of STS, BO, and CS among MHPs working in this sphere of care.

\section{Design}

To address the research questions, a survey based ex-post facto descriptive design was implemented as the ProQOL and resiliency constructs naturally occur within the context of counseling and therapy with suicidal clients in crisis stabilization settings. According to Heppner, Wampold, and Kivlighan (2008), ex-post facto descriptive designs allow for the investigation of how independent variables affect dependent variables in naturalistic settings.

\section{Participants}

The participant pool included 85 male and female licensed mental health professionals (MHPs) with varying levels of clinical experience. All participants worked in the inpatient setting and provided counseling and therapy services on crisis stabilization or acute care units. Participants were at least master's level clinicians and were appropriately licensed service providers. Medical mental health professionals were not included in the research sample.

Previous research findings have demonstrated that licensure type is not significantly related to the onset of the negative effects of helping among non-medical mental health 
practitioners that work with trauma (Sprang, Clark, \& Whitt-Woosley, 2007). Therefore, postmaster's years of experience was included as a predictor variable, but the specific type of licensure was not considered.

According to Ghahramanlou and Brodbeck (2000), Badger et al. (2008), and Craig and Sprang (2010), younger and less experienced clinicians who work with trauma and experience occupational stressors appear to be at high risk for the development of compassion fatigue (CF). Thus, clinician years of experience, specifically, years of experience working in acute/crisis settings was included as a relevant demographic and predictor variable.

Past results have demonstrated that clinician gender is an important variable that warrants attention when attempting to make conclusions about the nature of the adverse effects of helping among trauma workers. For example, Sprang et al. (2007) demonstrated that female gender appeared to be associated with higher levels of CF when compared to males. Therefore, the gender of participants was collected for this study and was included in the data analysis to determine if this relationship existed among MHPs working in crisis settings.

High frequencies of contact or exposures to PTSD clients and other difficult case presentations has consistently shown to be related to the onset of the negative effects of helping among trauma workers (Baird \& Kracen, 2006). However, no studies have assessed for how the frequency of contact with clients admitted to inpatient care due to suicidal gestures impacts the development of adverse effects of helping among crisis/acute clinicians. Therefore, participants were asked to provide an estimate of the number clients on their current caseloads who were admitted to facility due to suicidal behaviors. 


\section{Recruitment}

Participants for this study were recruited primarily through email. Contact information for clinical directors and clinical staff working on acute/crisis wards was found online through Google searches and through examination of an online predoctoral internship site directory known as the Association of Psychology Postdoctoral and Internship Centers (APPIC) website. This directory is public and freely available online. Clinical directors and clinical staff were viewed as gatekeepers and represented the first point of contacts. This approach verified that selected participants were indeed active and licensed mental health professionals working within the sphere of interest.

Through my clinical experiences, I have developed professional contacts with a range of crisis and acute care facilities that provide services to adults in the states of Arkansas, Tennessee, and West Virginia. These facilities were approached initially. However, to assure an adequate sample size, other facilities were selected based on internet searches using the terms: crisis unit, acute psychiatric hospital, non-profit/for-profit psychiatric hospital, acute crisis units, state hospital acute units, crisis stabilization unit, VA crisis unit, inpatient unit, and inpatient psychiatric acute/crisis unit. Only facilities in the United States were contacted and no facilities were contacted that operated in either Alaska or Hawaii.

\section{Sampling Approach}

In being a survey-based study, it was difficult to assure a random sample. Therefore, a purposive sampling approach was required and utilized. In defense of this sampling approach, Kruskal and Mosteller (1979) suggested that nonrandom samples are often "good enough" for the purposes of a particular study. One aim of this study was to gather a snapshot in time of the prevalence of burnout, secondary traumatic stress, and compassion satisfaction among an active 
sample of clinicians. In addition, the study was designed to determine what factors are related to the onset of compassion satisfaction within the sample. Although nonrandom samples can limit generalizability on many occasions, this risk must be weighed against the potential knowledge lost through implementing a more controlled design. I believe a survey based design was the rational and theoretically appropriate choice when considering the scope and nature of the research questions proposed. Furthermore, it would be impossible and unethical to replicate the psychological demands that may be associated with the treatment of suicide in inpatient settings.

\section{Power Analysis}

According to Cohen (1992), researchers must understand the required sample size in order to determine adequate power levels and effect size. For example, the total sample size will increase the power of a statistical test but a decrease in effect size also belays a decrease in $\alpha$. (Cohen, 1992). Cohen illustrated that an effective power analysis must consider and involve the relationship between four variables: sample size $(n)$, significance criterion $(\alpha)$, population $E S$ (effect size), and statistical power (Cohen, 1992).

This study represented the application of four statistical procedures on a single sample of participants. Four separate multiple regression analyses were conducted to address the research questions and to assess the relationships between the following predictor variables: clinician resiliency level, frequency of contact with suicidal clients, post-master's years of experience, and gender. The primary criterion variables included the ProQOL Version 5 subscale scores (Burnout, Secondary Traumatic Stress, and Compassion Satisfaction).

In determining the sample size and power of these procedures, a pragmatic approach suggested that the statistical procedure that requires the largest sample size will ultimately determine the total sample size needed as subsequent analyses will require fewer participants to 
maintain adequate discriminatory power. Additionally, the ProQOL Version 5 is a single measure that produces three separate composite scores (Secondary Traumatic Stress, Burnout, and Compassion Satisfaction), thus only one administration of the measure was required.

Cohen (1992) recommended a general power level of at least .80 for hypothesis testing procedures. Additionally, because four differing statistical tests were conducted on the same sample, the Bonferroni correction was used to control for type I error inflations. With four tests, the modified $p$ value for testing significance was set at $p<.01$. Tabachnick and Fidell (2007) provided this formula $\mathrm{N}>50+8 \mathrm{~m}$ to determine the sample size needed for multiple regression analysis with m equaling the number of predictors. Hypothesis four contains three predictor variables and one criterion variable. Therefore, this hypothesis required the largest sample size. In using Tabachnick and Fidell's (2007) formula as a guide $(50+8 \times 3)$ at least 74 participants were needed. However, according to Cohen (1992), multiple regression with three predictors while maintaining medium effect requires 108 participants $(\alpha=.01,1-\beta=.80)$.

A priori analysis conducted via G-Power Version 3.1.3, with linear multiple regression: fixed model, single regression coefficient selected and three predictors present $(\mathrm{ES}=.15, \alpha=.01$, $1-\beta=.80)$ indicated that a sample size of 84 participants was required (Erdfelder, Faul, \& Buchner, 1996). A priori analysis with linear multiple regression: fixed model, single regression coefficient selected and two predictors present $(\mathrm{ES}=.15, \alpha=.01,1-\beta=.80)$ indicated that a sample size of 82 was required (Erdfelder et al., 1996). These sample size estimates appeared consistent with both Tabachnick and Fidell's (2007) and Cohen's recommendations (1992), demonstrating a middle ground estimate. Therefore, for the hypotheses and analysis described in the Analysis section, at least 84 participants were required for data analysis. 


\section{Predictor Variables}

Frequency of Contact. Previous studies demonstrated that consistent exposures to clients presenting with PTSD and other chronic mental health concerns can be associated with the development of the adverse effects of helping (Sprang et al., 2007). In viewing exposure to clients presenting with suicide in a similar conceptual light, it is hypothesized that increased exposures to suicidal presentations may lead to higher scores of burnout and compassion fatigue and lower scores of compassion satisfaction. On the demographic survey, participants were asked to identify the number of active clients on their caseload who were admitted to care due to suicidal ideations or behaviors.

Gender. Gender of licensed mental health professionals working in the acute/crisis was collected via demographic survey and was included as a predictor variable. Multiple regression analysis was used to examine the relationship between gender (males versus females) and compassion satisfaction among MHPs working with suicide in the acute/crisis stabilization setting.

Years of Experience. The number of years of experience among licensed mental health professionals working in the acute/crisis units was collected through a demographic survey. This variable was included as a predictor variable in multiple regression analysis examining this relationship with compassion satisfaction among MHPs working with suicide in the acute/crisis stabilization setting.

Clinician Resiliency. Clinician resiliency scores, as measured by the Resiliency Scale14 (RS-14), were viewed as a predictor variable within this study in that it was hypothesized that varying levels of resiliency would produce differing levels of association with the criterion variables (Wagnild \& Young, 2011). For example, the constructs of resiliency and compassion 
satisfaction are theoretically similar, as high levels of each suggest intact functioning among helpers in both personal and professional domains. However, and to date, no published studies have specifically addressed the potential concurrent and discriminant relationships between resiliency and compassion fatigue and compassion satisfaction. Therefore, this study represented an exploration of the potential relationships between these constructs.

\section{Dependent Variables (Measures)}

Professional Quality of Life Scale Version 5 (ProQOL; Stamm, 2010). The Professional Quality of Life Scale (ProQOL) is a 30-item self-report measure used to assess for secondary traumatic stress (STS), compassion satisfaction (CS), and burnout (BO) (Stamm, 2010). Through interpreting and analyzing scores on the STS and BO subscale scores it is possible to make estimations about the risk for the development of compassion fatigue $(\mathrm{CF})$. The measure utilizes a 1 to 5 Likert scale, and respondents are asked to choose a response $(1=$ Never $; 2=$ Rarely $; 3=$ Sometimes $; 4=$ Often $; 5=$ Very Often $)$ that best describes their experience associated with a given statement (e.g., My work makes me feel satisfied; I am happy; I feel invigorated after working with those I help; I feel bogged down by the system). See C for further examples.

In the late 1980s and early 1990s, Stamm and Figley worked collaboratively to develop a more robust measure of the compassion fatigue and compassion satisfaction constructs. According to Stamm (2010), the ProQOL is a commonly used measure in research that examines the potential toll of working with individuals who have experienced stressful life events. The current measure has undergone four revisions in an attempt to improve the measure's psychometric properties. For this study, the ProQOL Version 5 will be implemented as this is 
the latest version available. This measure can be used freely for research or educational purposes.

The ProQOL Version 5 is not intended for use as a diagnostic tool in determining PostTraumatic Stress Disorder (PTSD) or depressive episodes as described in the DSM-5 (American Psychiatric Association, 2013). Indeed, the symptoms or constructs identified by this measure may parallel symptoms commonly associated with PTSD and depression (Stamm, 2010). However, this is likely an inevitable artifact of the measure as those who are commonly measured by the ProQOL can and do experience vicarious and direct forms of trauma in their work settings (Stamm, 2010).

The ProQOL was created on the premise that the symptoms commonly associated with PTSD and depression are natural consequences of trauma work in general and therefore are not pathological reactions (Stamm, 2010). The measure was first developed to be used as a screening and research tool to assess an individual's or organization's balance between the negative and positive aspects of helping (Stamm, 2010). Originally developed in English, it has now been translated and is available in Finnish, French, German, Hebrew, Japanese, Spanish, and Croat (Stamm, 2010).

Three subscales exist within the ProQOL Version 5 examining (a) burnout, (b) secondary traumatic stress, and (c) compassion satisfaction. Each scale consists of 10 items. To date, a single composite score is unavailable due to internal consistency issues and overlap between subscale scores (Stamm, 2010). However, according to Stamm (2005), the measure has demonstrated adequate construct validity, and there is empirical evidence suggesting that the measure has been effective in reducing the known collinearity between secondary traumatic stress and burnout (Stamm, 2005). 
Stamm (2005) reported that multi-trait, multi-method analysis has supported the discriminant power of the measure. Through investigation of a data bank consisting of completed administrations of the measure, the author of the instrument reported that the Compassion Satisfaction subscale has accounted for $5 \%(r=-.14 ; c o-\sigma=2 \% ; n=1187)$ of the shared variance between the burnout scale and $2 \%(r=-.23 ; c o-\sigma=5 \% ; n=1187)$ of the shared variance with the Secondary Traumatic Stress subscale, formally known as the Compassion Fatigue subscale (Stamm, 2005, 2010). Shared variances between the Burnout and Secondary Traumatic Stress subscales have been higher (21\%) suggesting that levels of distress are significant components of each of these scales (Stamm, 2005, 2010).

Craig and Sprang (2010) found the Cronbach alphas for the three scales to be at permissible levels: $\mathrm{CS}=.86 ; \mathrm{STS}=.71 ; \mathrm{BO}=.77$ and reported that test-retest correlations have shown that the measure is adequate. However, Craig and Sprang (2010) conducted exploratory factor analysis (EFA) with the ProQOL Version III and their results did not demonstrate a 30item, three factor structure. Rather, their results demonstrated a 24 item, three-factor structure (Craig \& Sprang, 2010). Specifically, alpha reliabilities for the Compassion Satisfaction subscale were .80, Compassion Fatigue subscale .73, and Burnout subscale .81 (Craig \& Sprang, 2010). These alpha reliability scores only reached acceptable levels as noted above after two items from the Compassion Satisfaction subscale were removed (Craig \& Sprang, 2010). The removed items remain on the ProQOL Version 5 and are: "I have beliefs that sustain me" and "I feel connected to others". Per Craig and Sprang's (2010) findings, these items will be removed and will be treated as missing data during scoring procedures. Currently, these findings are the only publically available results that specifically describe the instrument's factor analytic structure. 
Past research findings have demonstrated sound validity. For example, Potter et al. (2010) were able to demonstrate that nurses working with terminal cancer patients showed increased levels of compassion fatigue when they were required to work with more problematic patients (Potter et al., 2010). Musa and Hamid (2008) assessed levels of distress among rescue workers in Sudan using the Professional Quality of Life Survey R-III and found that burnout appeared to be positively correlated with feelings of malaise and other symptoms commonly associated with secondary traumatic stress. Most importantly, the results of Musa and Hamid (2008) showed that the measure was effective in demonstrating how burnout and secondary traumatic stress were distinct from the compassion satisfaction construct.

Scoring. Scoring of the ProQOL is a three-step process. First, identified items must be reversed as defined in the test manual. The second step is to sum items by subscale. The third is to covert raw scores to T-scores $\left(\overline{x^{-}}=50, \mathrm{SD}=10\right)$. This can be done by hand or by statistical software. The instructions for both methods are supplied in the test 2010 test manual.

Burnout. High scores on the Burnout subscale suggest that an individual is at risk for experiencing symptoms of burnout as manifested in feelings of hopelessness and helplessness in their work environments. Within the measure, burnout is considered to be one aspect of the compassion fatigue construct. Test validation has shown the mean score on the Burnout subscale is $M=50(S D=10, \alpha=.75)$, that roughly $25 \%$ of respondents score above 57 , and about $25 \%$ of people score below 43. Scores below 18 suggest minimal levels of burnout and scores greater than 57 suggest high levels of burnout (Stamm, 2010).

Secondary Traumatic Stress. High scores on the Secondary Traumatic Stress (STS) subscale suggest that a person is at high risk for compassion fatigue. STS is considered to be the second factor associated with development of compassion fatigue. Test validation data has 
shown that the average score on this scale is $M=50(S D=10, \alpha=.81)$ (Stamm, 2010). Stamm reported that roughly $25 \%$ of respondents generally score below 43 and $25 \%$ of respondents score above 57 on this scale (2010). Scores higher than 57 are considered to be impaired and low scores are considered to be 43 or less, which are suggestive of minimal levels of STS (Stamm, 2010).

Compassion Satisfaction. High scores on the Compassion Satisfaction (CS) subscale suggest that a person is experiencing satisfaction with his or her abilities to function effectively as helpers within their work environment. The average score on this scale is $M=50(S D=10, \alpha$ $=.88$ ) and roughly $25 \%$ of respondents score higher than 57 and approximately $25 \%$ of respondents score below 43 (Stamm, 2010). High scores are considered to be favorable and greater than 57. Low scores are considered to be 43 or less, suggesting minimal levels of CS (Stamm, 2010).

Interpretation. Individual subscale scores are used to make conclusions about the nature of the professional quality of life. For example, high scores on the STS and BO subscales and low scores in CS subscale would suggest that an individual is experiencing high levels of compassion fatigue. Furthermore, these scores would suggest that an individual may feel “overwhelmed and useless in the work setting” (Stamm, 2010 p. 23). Descriptions of subscale score combinations are provided in the test manual and will be used as a guide when interpreting data.

14 Item Resilience Scale (RS-14) (Wagnild \& Young, 2011). The original Resilience Scale (RS) was published in 1993 and was advertised as the first measure developed to directly assess resiliency (Wagnild \& Young, 1993). According to the authors, since 2006, over 4,500 researchers, organizations, and clinicians have requested permission to access this scale for use 
with an array of populations (Wagnild \& Young, 2011). The original RS was developed in 1987 and was based on two qualitative studies that included 24 older women who were able to successfully weather significant life stressors (e.g., loss of a spouse, health decline, or employment change) and 39 caregivers of spouses with Alzheimer's disease (Wagnild \& Young, 1993). The initial RS consisted of 50 items which included statements encountered from the qualitative study with 24 older women (Wagnild \& Young, 1993). This initial measure demonstrated sound psychometric properties with alpha coefficients ranging from 0.84 to 0.94 . Furthermore, factor analysis on the initial RS demonstrated the presence of two major factors which were the "acceptance of self and life" and "personal competence" (Wagnild \& Young, 1993).

The shorter 14-item Resilience Scale (RS-14) was piloted five years after the publication of the RS and was developed to be a more succinct version of the parent instrument. Within the RS-14, 14 items were selected for inclusion into this briefer measure after principal component analysis showed that all items loaded onto a single component $>0.40$ (Wagnild \& Young, 2011). The eigenvalue for this factor was 7.29 and accounted for $52.1 \%$ of the variance (Wagnild \& Young, 2011). Additionally, the RS and RS-14 have demonstrated strong correlations ( $r=0.97$, $p<0.001$ ) as well as high levels internal of consistency between the two measures with alpha levels of .93 (Wagnild \& Young, 2011).

In 2010, visitors to the Resilience Scale Website were voluntarily asked to complete the RS-14 and 1,161 surveys were completed and included in this validation study (Wagnild \& Young, 2011). Participants were asked about their education, health status, frequency of depressive symptoms, gender, and age. The average age of participants was 36 years and $61 \%$ of the participants were between the ages of 18 and 40 . In terms of gender, $70 \%$ were female. In 
regards to education, 10\% reported high school or less, 18\% reported obtaining master's degrees, and $8 \%$ reported to obtaining doctoral degrees (Wagnild \& Young, 2011). About half of the sample reported "very good to excellent health" and 10\% reported "poor to fair health," and 25\% of sample reported few symptoms of depression with $17 \%$ of the sample reporting frequently feeling depressed (Wagnild \& Young, 2011).

Descriptive statistics from the 2010 study showed a mean score of 76.17 (moderate range) with a standard deviation of 13.9 , skewness of -1.143 and an alpha level of $0.93(n=$ 1,161). Multivariate regression revealed that age, health status, and depression appear to be independently associated with varying levels of resilience. For example, greater age, adequate health and low levels of depression predicted higher RS-14 scores $(\beta=0.25$ for depression, $\beta=$ 0.24 for health, and $\beta=0.15$ for age) (Wagnild \& Young, 2011).

Measures tapping similar constructs should be highly correlated and the RS-14 has been compared with the Health Promoting Lifestyle Profile (HPLP) which is measure with proven psychometric properties that assesses six domains including: stress management, health responsibility, nutrition, exercise, self-actualization, and interpersonal support. The RS-14 has demonstrated moderate to high correlations with the HPLP subscales similar in content to the RS-14 ( $r>0.45)$ (Wagnild \& Young, 2011).

The RS-14 has also demonstrated adequate discriminant validity when compared to nonrelated scales included in the HPLP such as nutrition $(r=0.29)$ and exercise $(r=0.29)$ with $n=707$ (Wagnild \& Young, 2011). The measure has also demonstrated adequate concurrent validity when compared to the Life Satisfaction Index-A $(r=0.37)$, the Philadelphia Geriatric Center Morale Scale $(r=0.3)$, and with the Beck Depression Inventory (BDI) $(r=0.41)$ (Wagnild \& Young, 1993). 
Scoring and Interpretation. The RS-14 uses a seven-point Likert scale. Respondents read a positively worded declarative statement and choose a number from 1 to 7 (1=strongly disagree to $7=$ strongly agree) that best describes their experiences (see appendix B for examples). The RS-14 uses a total or composite score to determine resiliency level as this is a single factor measure. Scores can range from 14-98. Scores from 14-56 demonstrate very low levels of resilience, which suggest feeling overwhelmed, low energy, anxiety, and depression. Scores of 57-64 demonstrate low levels of resiliency suggestive of feelings of general dissatisfaction, low levels of anxiety and depression, and pessimism. Scores of 65-73 represent low-end levels, which may indicate feeling unfulfilled, feeling unappreciated, and feeling a lack of control. Scores ranging from 74-81 represent moderate levels of resiliency, which may be manifested in fluctuating energy levels, increased optimism but still some focus on negative aspects of life. Scores ranging from 82-90 represent moderately high levels of resiliency manifested in increased optimism, fewer depressive symptoms but some focus on unsatisfactory aspects of life, and the realization for need of some changes. Finally, scores ranging from 91-98 represent high levels of resiliency which can represent intact functioning, living a purposeful life, and having adequate coping abilities in the face of adversity (Wagnild \& Young, 2011).

\section{Procedure}

Crisis stabilization and acute care psychiatric facilities serving adult populations were identified through the author's professional contacts and through use of popular Internet browsers using search terms such as "psychiatric inpatient care" and "acute/crisis inpatient psychiatric care". Clinical directors and clinical staff working on acute wards were viewed as the gatekeepers and were instructed to share the email with the linked survey materials with other licensed clinical staff operating on acute/units. Facilities in the states of West Virginia, 
Tennessee, and Arkansas received precedent for inclusion in this study as the primary investigator had contact with many facilities in these states. However, to assure an adequate sample size, Internet searches were expanded. Facilities in all states excluding Hawaii and Alaska were contacted. The clinical directors' and clinical staff working on acute/crisis wards contact information was found online through Google searches and through examination of online predoctoral internship site directories such as the Association of Psychology Postdoctoral and Internship Centers (APPIC) website. This directory was publically available.

Once IRB exempt status was granted, clinical directors and clinical staff at acute/crisis facilities were contacted via email. Within this email, the directors and staff received a brief description of the study and a request instructing them to share the provided link with licensed mental health professionals who conducted therapy or other counseling services with adult clients in the crisis stabilization or acute psychiatric care environments (See Appendix D). This sampling style is sometime referred to as a snowball approach. Consent to participate in this study was acknowledged through receipt of completed surveys via Qualtrics and the risks and benefits of the study were outlined on the first page of the online survey (See Appendix E). If the clinical director or staff did not wish to consent to the terms of this study, the primary investigator was notified through email correspondence. Only four contacted facilities opted not to participate in this study.

Upon receiving a forwarded email from their clinical directors or other staff, participants found the survey powered by Qualtrics. Consent to participate in this study was acknowledged through completed and returned surveys. Once entering the Qualtrics link, participants were asked to complete a brief demographic survey, the 14-Item Resiliency Scale (RS-14), and the Professional Quality of Life Version-5 in that order (see appendices A, B, \& C). The brief 
demographic survey asked participants to provide the following information: age, gender, number estimate of clients on their inpatient caseloads, estimate of the number of clients on their inpatient caseload admitted due to suicidal ideations or behaviors, and the clinician's years of experience in working in the acute/crisis setting. It was estimated that it would take no longer than 25 minutes to complete the survey material and the average completion time was approximately 11 minutes. Names or other identifying information were not included, and completed test data was available to the primary investigator and the doctoral committee.

Qualtrics assigned an identifying number to completed surveys, and this number was used to track responses and to determine outliers during data analysis. However, participants were informed that their participation in this study would make them eligible for a raffle to receive a 100-dollar gift card from the Target retail store. If they were interested in participating in this raffle they were required to provide their email at the bottom of the demographic survey. A winner was randomly selected in February of 2015. Following completion of this study, participants were able to contact the primary investigator via email with any questions or comments they may have in regards to the scope of the research. This information was included on the final page of the Qualtrics survey.

\section{Analysis}

This dissertation attempted to quantitatively describe the professional quality of life (ProQOL) among MHPs who regularly work with adult suicidal clients in the crisis stabilization setting. Within the ProQOL concept exists three constructs known as secondary traumatic stress (STS), burnout (BO), and compassion satisfaction (CS). These constructs where included as the primary criterion variables as measured by the Professional Quality of Life Scale Version 5. In addition, clinician resiliency, frequency of contact (FOC) with clients admitted due to suicidal 
behaviors, gender, and post-master's years of experience was included as predictor variables so as to explore the possible associations with the ProQOL Version 5 constructs included the professional quality of life paradigm. Data were analyzed through SPSS Version 18.0. Due to sample size limitations, data analysis was conducted on a single sample. Therefore, to reduce the possibility of Type I errors occurring, the Bonferroni correction was applied and the significance value will be adjusted to .01 level (Cohen, 1992).

Hypothesis 1. It is predicted that high frequencies of contact with suicidal clients and low levels of resiliency will be associated with increased scores on the Burnout subscale of the ProQOL Version-5. For this analysis, scores on the Burnout subscale will be selected as the primary criterion variable. Two predictor variables are identified and include the frequency of contact with suicidal clients and resiliency variables. This hypothesis will be tested through multiple regression analysis. The two identified predictor variables will be entered into the model in a standard fashion.

Hypothesis 2: It is predicted that high frequencies of contact with suicidal clients and low levels of resiliency will be associated with increased scores on the Secondary Traumatic Stress subscale of the ProQOL Version-5. For this analysis, scores on the Secondary Traumatic Stress subscale will be selected as the primary criterion variable. Two predictor variables are identified and include the frequency of contact with suicidal clients and resiliency variables. This hypothesis will be tested through multiple regression analysis. The two identified predictor variables will be entered into the model in a standard fashion.

Hypothesis 3: It is predicted that fewer frequencies of contact with suicidal clients and high levels of resiliency will be associated with favorable scores on the Compassion Satisfaction subscale of the ProQOL Version-5. For this analysis, scores on the Compassion Satisfaction 
Stress subscale will be selected as the primary criterion variable. Two predictor variables are identified and include the frequency of contact with suicidal clients and resiliency variables. This hypothesis will be tested through multiple regression analysis. The two identified predictor variables will be entered into the model in a standard fashion.

Hypothesis 4: It is predicted that female gender, fewer years of post-master's clinical experience, and higher frequencies of contacts with clients admitted to care due to suicidal behaviors will be associated with decreased scores on the Compassion Satisfaction subscale as measured by the ProQOL Version-5. For this analysis, scores on the Compassion Satisfaction subscale will be selected as the primary criterion variable as an absence of compassion satisfaction suggests increased levels of both secondary traumatic stress and burnout (Stamm, 2010).

This hypothesis will be tested through hierarchical multiple regression analysis. Gender will be entered into the regression model first as previous studies have that demonstrated that female gender is significantly related to the onset of compassion fatigue among trauma workers $(\beta=.85, N=1,121)$ (Sprang, Clark \& Whitt-Woosley 2007). Post-master's years of experience will be entered second as the results of many previous studies in the area have demonstrated that increased age and clinical experience may be associated with favorable levels of compassion satisfaction. Frequency of contact will be entered last as it is unknown how this variable factors into the proposed relationship. 


\section{Chapter 3}

\section{Results}

Data were collected over a five-month time frame during the summer of 2014 (May through September) and participants were recruited via email. In total, 736 emails were sent to clinical directors and staff at 278 facilities with crisis and acute inpatient treatment. In some cases, multiple emails were sent as reminders to clinical directors at facilities due to no response. Facilities in Southeast region of the United States were initially targeted but due to limited and incomplete responses, emails were then sent to inpatient and acute and crisis facilities across the United States. Over the course of data collection, only four facilities declined participation.

In total, 96 surveys were returned complete or partially complete. An additional 14 responses were collected showing that the survey was opened but not started within the Qualtrics program. Of the 96 returned surveys, 11 were incomplete and not included in data analysis leaving 85 completed surveys in total. Among these 85 surveys, three participants skipped one item each. These missing three data points were replaced with the mean score during data analysis procedures. Therefore, the final sample included 85 participants satisfying the power requirements $(\mathrm{ES}=.15, \alpha=.01,1-\beta=.80)$. Tentatively, the overall survey response rate was $11.5 \%$ but this rate must be interpreted with caution as it impossible to know how many participants may have been exposed to the survey materials and simply did not respond. This was unavoidable artifact of the purposive and snowball sampling approaches.

\section{Descriptive Results}

In total, $28(32.9 \%)$ male and $57(67.1 \%)$ female participants were included for data analysis. The average age of all participants was 43.08 years, ranging from 25 years to 70 years. The average years of experience (YOE) working in inpatient crisis or acute settings, as mental 
health professionals, was 11.71 years and ranged from 1 year to 41 years. The average reported number of clients carried on an inpatient caseload admitted to care due to suicidal behaviors was 11.57 clients, ranging from 0 to 100 clients. The average general caseload not specifying suicidality was 23.02 clients and ranged from 1 client to 100 clients.

Internal consistency analysis of the ProQOL Version 5 subscales showed all scales to be within acceptable limits. Somewhat contrary to Craig and Sprang's (2010) finding with two items removed $(\alpha=.65)$, the burnout subscale demonstrated slightly better internal consistency when all items were included $(\alpha=.69)$. Therefore, all items were included in subsequent data analysis procedures. The compassion satisfaction subscale showed the highest level of internal consistency $(\alpha=.87)$ and secondary traumatic stress scale showed an adequate level $(\alpha=.79)$. Internal consistency analysis of the Resiliency Scale-14 also demonstrated an adequate Cronbach's alpha score $(\alpha=.79)$.

Participant responses on the ProQOL Version-5 burnout, compassion satisfaction, and secondary traumatic stress subscales indicated that approximately $18.8 \%$, or 16 participants, scored in the high range on the burnout subscale (See Table 1). Interestingly, no participants scored in low ranges on the burnout subscale. However, low scores on this scale are considered to be 18 or less after t-scale conversion (Stamm, 2010). Most participants demonstrated average scores on this scale $(n=69,81.2 \%)$. Score ranges were defined by the ProQOL Version-5 manual and are expressed in t-scores (Low $=18$ or less, Average $=18$ to 57 , High $=57$ and above) (Stamm, 2010). 
Table 1

Burnout Scores by Number of Participants and Percentages

\begin{tabular}{ccc}
\hline Range & Number of Participants & Percentage of Participants \\
\hline Low (0-17) & 0 & $0 \%$ \\
Average (18-56) & 69 & $81.2 \%$ \\
High (57+) & 16 & $18.8 \%$ \\
Total & 85 & $100 \%$ \\
& & \\
\hline
\end{tabular}

Approximately $22.4 \%$, or 19 participants, scored in both the high and low ranges on the secondary traumatic stress subscale (See Table 2). Most participants scored in the average range on this scale $(n=47,55.3 \%)$. Score ranges were defined by the ProQOL Version-5 manual and are expressed in t-scores (Low $=$ Less than 43 , Average $=43$ to 57, High $=57$ and above) (Stamm, 2010).

Table 2

Secondary Traumatic Stress Scores by Number of Participants and Percentages Range Number of Participants Percentage of Participants Low (0-42) 19 $22.4 \%$ Average (43-56) 
High (57+)

Total
19

85
$22.4 \%$

100

Approximately $16.5 \%$, or 14 participants, scored in the low range. The majority of sample scored in the average range $(n=47,55.3 \%)$ and 24 participants, or $28.2 \%$, scored in the high range (See Table 3). Score ranges were defined by the ProQOL Version-5 manual and are expressed in t-scores (Low $=$ Less than 43 , Average $=43$ to 57 , High $=57$ and above) (Stamm, 2010).

Table 3

Compassion Satisfaction Scores by Number of Participants and Percentages

\begin{tabular}{ccc}
\hline Range & Number of Participants & Percentage of Participants \\
\hline Low (0-42) & 14 & $16.5 \%$ \\
Average (43-56) & 47 & $55.3 \%$ \\
High (57+) & 24 & $28.2 \%$ \\
Total & 85 & 100 \\
& & \\
\hline
\end{tabular}

Descriptive statistics for the Resiliency Scale-14 showed that the average score across the sample was 83.61 , ranging from 57 to 98 . The majority of the sample (37.6\%) scored in the moderately high range $(n=32)$ indicating healthy levels of resiliency. Only two participants 
scored in the low range and 20 participants, or $20 \%$, of the sample scored in the high range. See Table 5 for a more detailed description of these results.

Table 5

Resiliency Scale 14 Scores by Number of Participants and Percentages

\begin{tabular}{ccc}
\hline Range & Number of Participants & Percentage of Participants \\
\hline Very Low (14-56) & 0 & $0 \%$ \\
Low (57-64) & 2 & $2.4 \%$ \\
On the Low End (65-73) & 8 & $9.4 \%$ \\
Moderate (74-81) & 23 & $27.1 \%$ \\
Moderately High (82-90) & 32 & $37.6 \%$ \\
High (91-98) & 20 & $23.5 \%$ \\
Totals & 85 & $100 \%$ \\
& & \\
\hline
\end{tabular}

\section{Regression Diagnostics for Hypothesis 1}

Regression diagnostics were conducted to determine if the assumptions of multiple regression analysis were violated. Multicollinearity was assessed through examination of correlations between predictors. Multicollinearity occurs when predictor variables are overly correlated with one another (Field, 2009). The results of this model did not demonstrate the presence of multicollinearity as no high correlations $(>.80)$ were encountered between predictors. The model also produced a Durbin-Watson statistic of 1.76 suggesting that 
autocorrelation was not a problem. Additionally, VIF (variance inflation factors) greater than 10 are sometimes indicative of multicollinearity and VIF scores within this model appear well below this level (Field, 2009). See Table 7 for a more detailed description of these results.

Homogeneity of Variance, or Homoscedasticity, was next assessed. Homoscedasticity refers to the assumption that variance is uniformly spread between criterion and predictor variables (Field, 2009). This assumption was examined through a scatterplot of residuals produced in SPSS (See figure 1). No correlations appeared evident within this plot suggesting that the assumption of homoscedasticity was not violated.

Figure 1: Scatterplot of Studentized Residuals

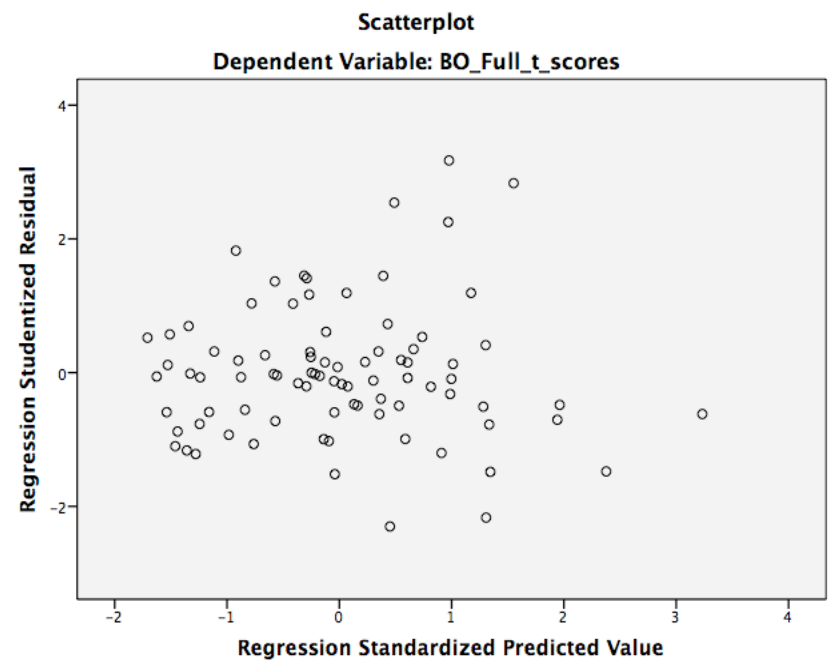

Normality of residuals was assessed through examining a Partial Plot and Histogram produced by SPSS. The Partial Plot (see Figure 2) showed that predictor variables (FOC \& Resiliency) appeared to have a generally linear relationship with the criterion variable (Burnout Scores) and Figure 3 shows an approximately normal distribution of residuals. Therefore, the assumption of normality was met. 
Figure 2: P-P Plot of Standardized Residuals

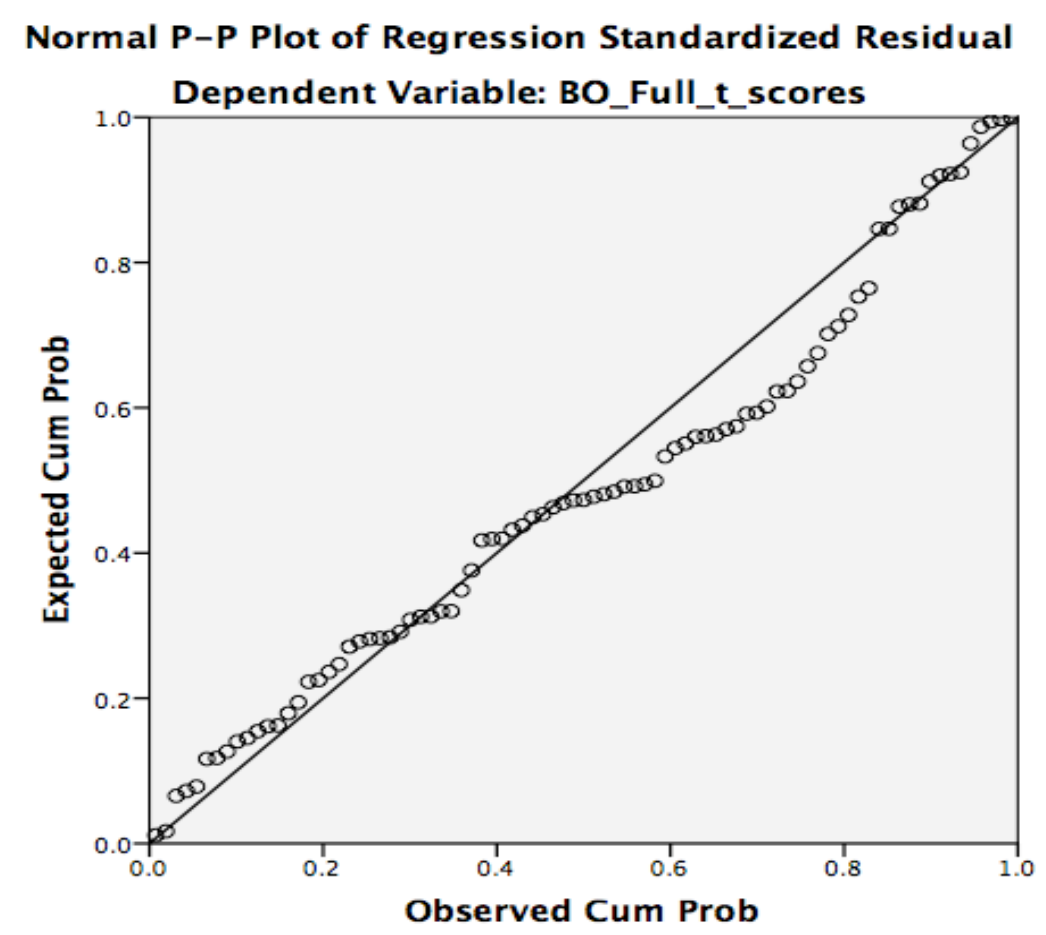

Figure 3: Histogram of Standardized Residuals

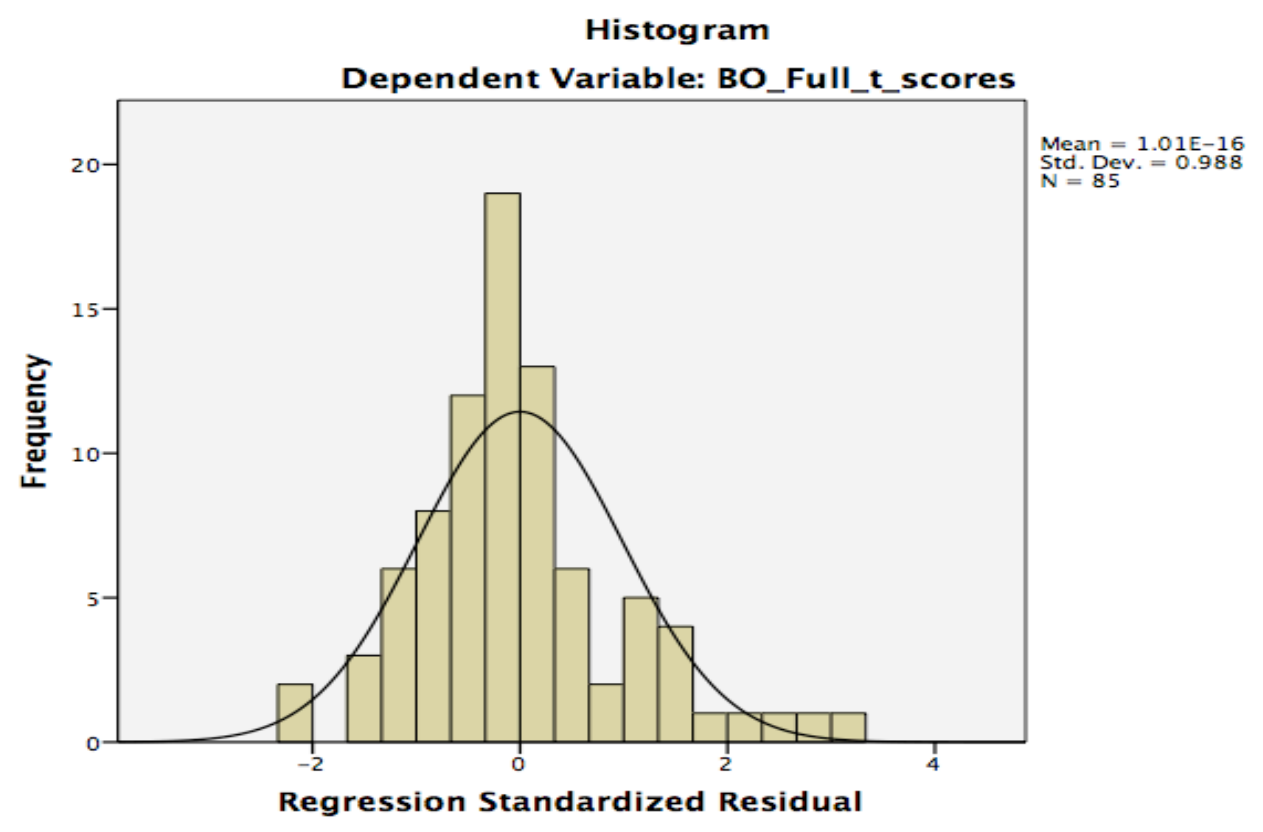

To examine whether or not certain cases or outliers overly influenced the model, Cook's distance was calculated. The Cook's distance is a measure of the influence of single cases on the 
model, and scores greater than one indicate that certain cases may be overly influencing the model (Field, 2009). The maximum encountered Cook's distance, as calculated from residual statistics, was .133. This finding indicated no undue influence from a single case.

Hypothesis 1 Results. A multiple linear regression analysis was conducted to evaluate how well frequency of contact (FOC) and resiliency levels predicted burnout subscale scores on the ProQOL Version 5 with frequency of contact (FOC) and resiliency levels entered into the model as predictor variables. Overall, the linear composite of the independent variables entered into the regression procedure predicted $27 \%$ of the variance in the burnout subscale scores $F(2$, $82)=16.49, p<.0001$, adj. $R^{2}=.27$ (See Table 6$)$. The $b$-values included within the coefficient table (see Table 7) showed that lower levels of resiliency significantly predicted increased burnout scores, as the $b$-value was negative. However, increased frequency of contact (FOC) did not meaningfully or significantly contribute to the model's predictive ability.

Table 6

ANOVA

\begin{tabular}{llrrrrr}
\hline Model & & Sum of Squares & df & Mean Square & F & Sig. \\
\hline \multirow{2}{*}{1} & Regression & 2409.882 & 2 & 1204.941 & 16.495 & $.000^{\mathrm{b}}$ \\
& Residual & 5990.118 & 82 & 73.050 & & \\
& Total & 8400.000 & 84 & & & \\
\hline
\end{tabular}

a. Dependent Variable: Burnout b. Predictors: FOC, RS-14 
Table 7

Coefficients

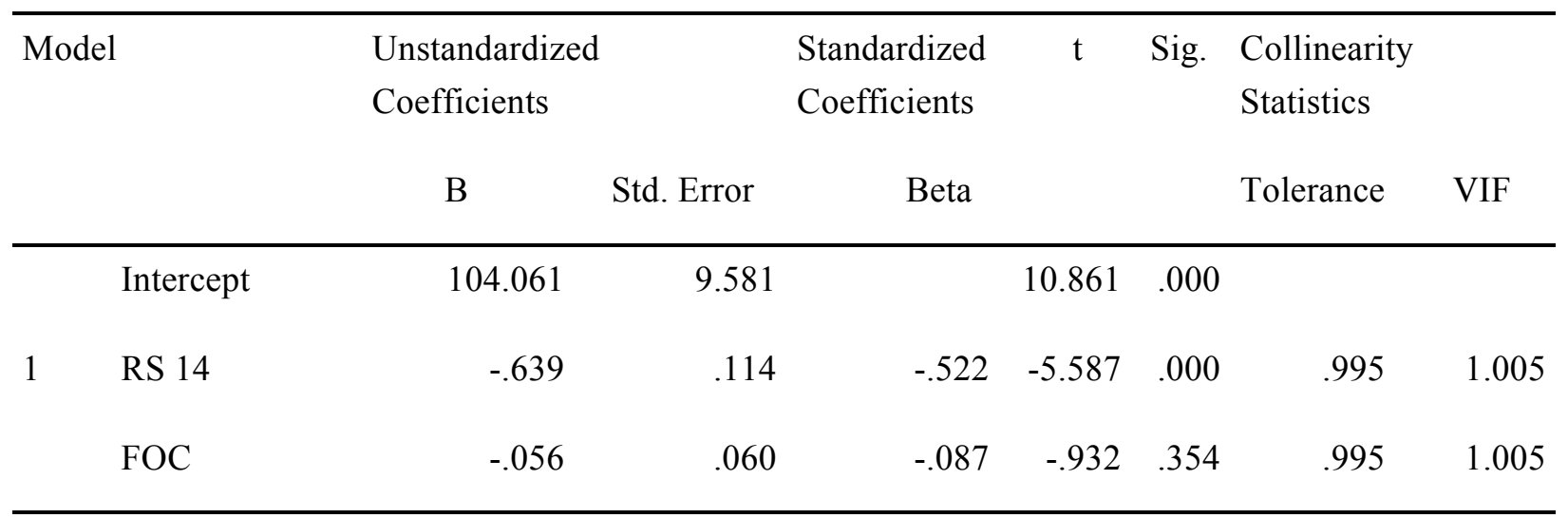

a. Dependent Variable: Burnout

b. Note.RS-14 = Resiliency Scale 14, FOC= Frequency of Contact

Hypothesis 2 Results. A multiple linear regression analysis was conducted to predict secondary traumatic stress subscale scores on the ProQOL Version 5 with frequency of contact (FOC) and resiliency level entered into the model as predictor variables. The analysis suggested that FOC and resiliency did not significantly predict variance in secondary traumatic stress $F$ (2, $82)=1.44, p>.01$, adj. $R^{2}=.01$. The data were screened and missing values or skipped items on survey questions were replaced with the mean scores across the sample for that specific survey item. See Table 8 below for a model summary. 
Table 8

ANOVA

\begin{tabular}{rlrrrrr}
\hline Model & & Sum of Squares & df & Mean Square & F & Sig. \\
\hline \multirow{3}{*}{1} & Regression & 285.933 & 2 & 142.967 & 1.445 & $.242^{\mathrm{b}}$ \\
& Residual & 8114.067 & 82 & 98.952 & & \\
& Total & 8400.000 & 84 & & & \\
\hline
\end{tabular}

a. Dependent Variable: Secondary Traumatic Stress b. Predictors: FOC, RS-14

\section{Regression Diagnostics for Hypothesis 3}

Regression diagnostics were conducted to determine if the assumptions of multiple regression analysis were violated. Multicollinearity was assessed through examination of correlations between predictors. Multicollinearity occurs when predictor variables are overly correlated with one another. The results of this model did not demonstrate the presence of multicollinearity as no high correlations $(>.80)$ were encountered between predictors. The model also produced a Durbin-Watson statistic of 1.65 suggesting that autocorrelation was not a problem. Additionally, VIF (variance inflation factors) greater than 10 are sometimes indicative of multicollinearity and VIF scores within this model appeared well below this level (Field, 2009). See Table 10 above for a more detailed description of this result.

Homogeneity of Variance, or Homoscedasticity, was next assessed. Homoscedasticity refers to the assumption that variance is uniformly spread between criterion and predictors variables. This assumption was assessed through examination of a scatterplot of residuals produced in SPSS (See figure 4). No correlations appeared evident within this plot suggesting that the assumption of homoscedasticity was not violated within this model. 
Figure 4: Scatterplot of Studentized Residuals

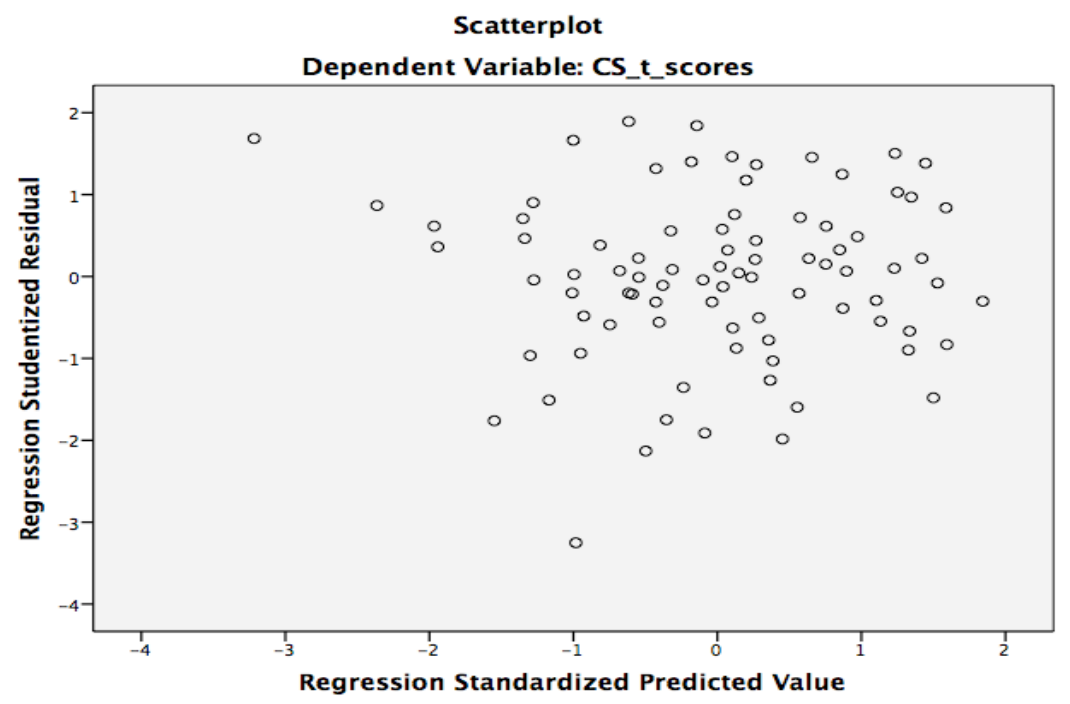

Normality of residuals was assessed through examining a Partial Plot and Histogram produced by SPSS. The Partial Plot (see Figure 5) shows that predictor variables (FOC \& Resiliency) appear to have a linear relationship the criterion variable (compassion satisfaction) and Figure 6 shows an approximately normal distribution of residuals. Therefore, the assumption of normality was met.

Figure 5: P-P Plot of Standardized Residuals

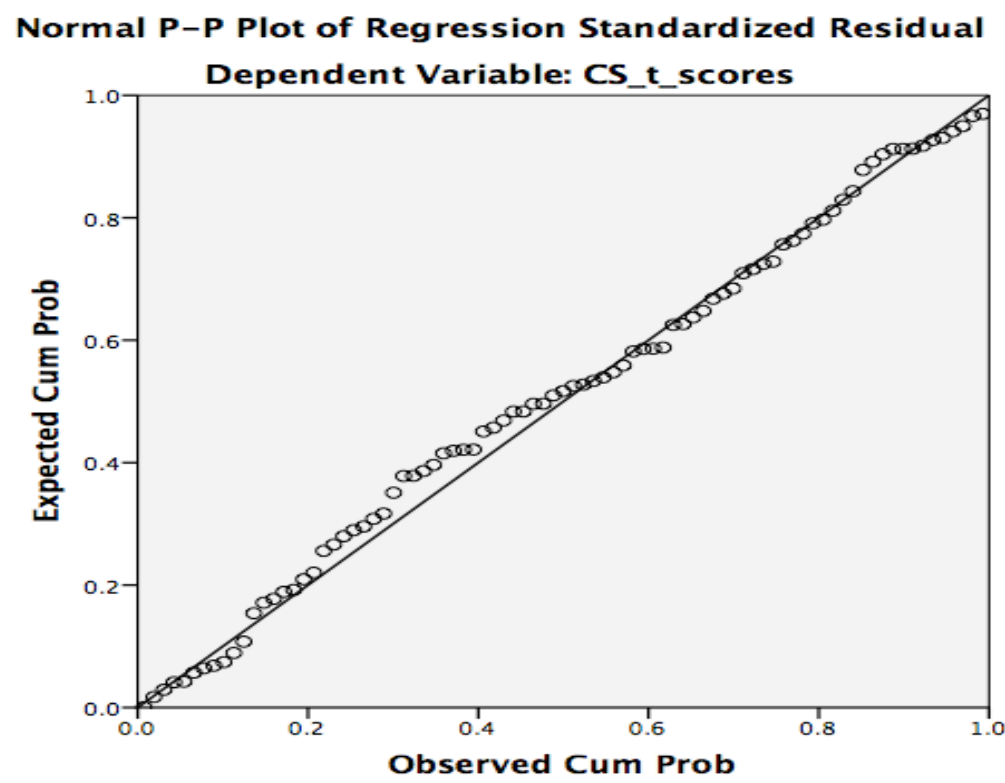


Figure 6: Histogram of Standardized Residuals

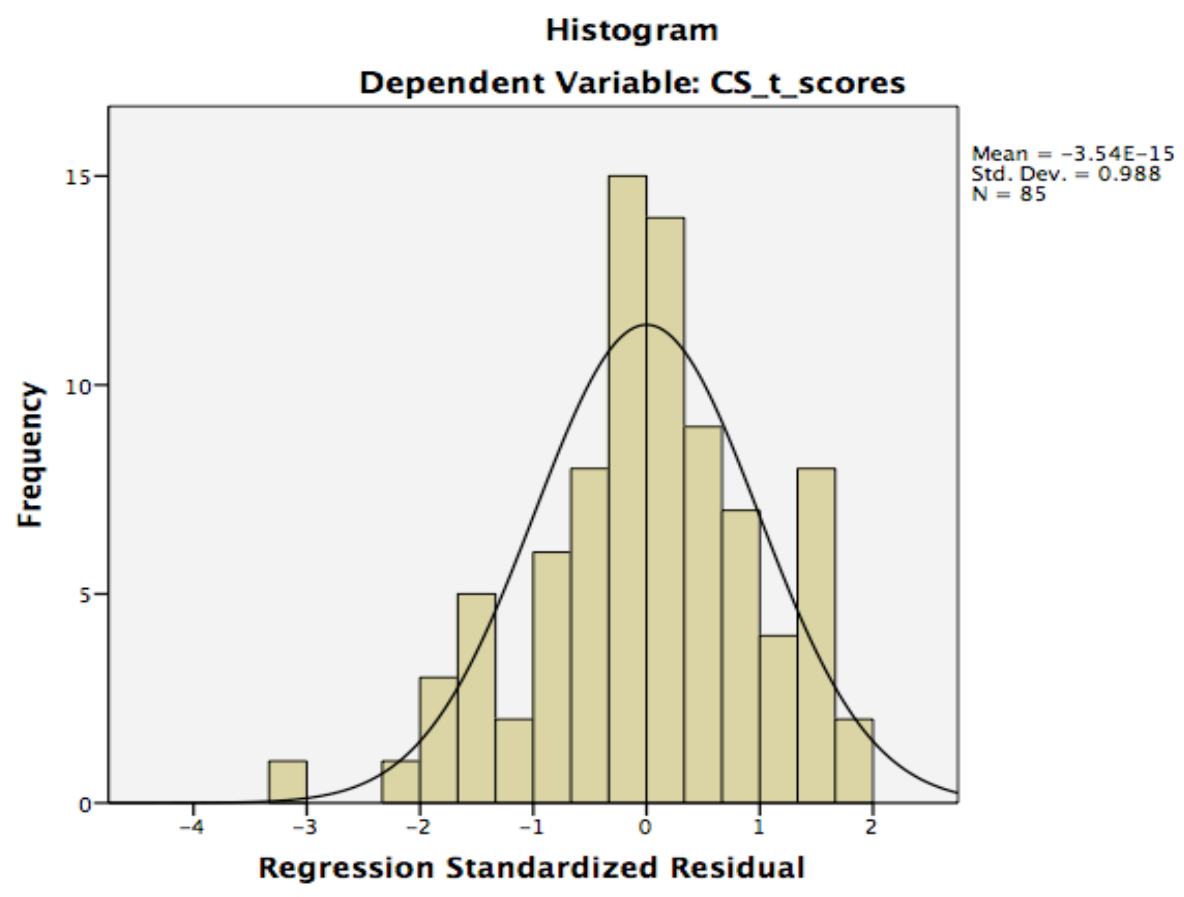

To examine whether or not certain cases or outliers overly influenced the model, Cook's distance was calculated. The Cook's distance is a measure of the influence of single cases on the model and scores greater than one indicate that certain cases may be overly influencing the model (Field, 2009). The maximum encountered Cook's distance, as calculated from residual statistics, was .92. This finding indicated no undue influence from a single case.

Hypothesis 3 Results. A multiple linear regression analysis was conducted to predict compassion satisfaction subscale scores on the ProQOL Version 5 with frequency of contact (FOC) and resiliency levels entered into the model as predictor variables. Overall, the linear composite of the independent variables entered into the regression model predicted $24 \%$ of the variance in the compassion satisfaction subscale scores $F(2,82)=14.56, p<.0001$, adj. $R^{2}=.24$ (See Table 9). The $b$-values included within the coefficient table (see Table 10) demonstrated that higher levels of resiliency significantly predicted increased compassion satisfaction scores. 
However, increased frequency of contact (FOC) was not found to be a significant predictor of decreased compassion satisfaction. The data were screened and all missing values or skipped items on survey questions were replaced with the mean scores across the sample for that specific survey item. Finally, possible violations of assumptions were assessed following the data analysis.

Table 9

ANOVA

\begin{tabular}{llccccc}
\hline Model & & Sum of Squares & df & Mean Square & F & Sig. \\
\hline \multirow{2}{*}{1} & Regression & 2202.977 & 2 & 1101.488 & 14.575 & $.000^{\mathrm{b}}$ \\
& Residual & 6197.023 & 82 & 73.050 & & \\
& Total & 8400.000 & 84 & & \\
\end{tabular}

a. Dependent Variable: Compassion Satisfaction b. Predictors: FOC, RS-14

Table 10

Coefficients

\begin{tabular}{|c|c|c|c|c|c|c|c|c|}
\hline \multirow{2}{*}{\multicolumn{2}{|c|}{ Model }} & \multirow{2}{*}{$\begin{array}{l}\text { Unstandardizec } \\
\text { Coefficients } \\
\text { B }\end{array}$} & & \multirow{2}{*}{$\begin{array}{r}\text { Standardized } \\
\text { Coefficients } \\
\text { Beta }\end{array}$} & \multirow[t]{2}{*}{$\mathrm{t}$} & \multirow[t]{2}{*}{ Sig. } & \multirow{2}{*}{$\begin{array}{l}\text { Collinearity } \\
\text { Statistics } \\
\text { Tolerance }\end{array}$} & \multirow[b]{2}{*}{ VIF } \\
\hline & & & Std. Error & & & & & \\
\hline & Intercept & -1.381 & 9.745 & & -.142 & .888 & & \\
\hline \multirow[t]{2}{*}{1} & RS 14 & .606 & .116 & .495 & 5.207 & .000 & .995 & 1.005 \\
\hline & FOC & .065 & .061 & .100 & 1.053 & .295 & .995 & 1.005 \\
\hline
\end{tabular}

c. Dependent Variable: Compassion Satisfaction

d. Note.RS-14 = Resiliency Scale 14, FOC= Frequency of Contact 
Hypothesis 4 Results. A multiple linear regression analysis was conducted to predict compassion satisfaction subscale scores on the ProQOL Version 5 with gender, years of experience (YOE), and frequency of contact (FOC) entered into the model hierarchically in the order mentioned above. Regression analysis suggested that gender, YOE, and FOC did not significantly predict variance in compassion satisfaction $F(2,82)=.87, p>.01$, adj. $R^{2}=-.003$. The data were screened and all missing values or skipped items on survey questions were replaced with the mean scores across the sample for that specific survey item. Finally, possible violations of assumption where assessed following data analysis. No significant violations of assumptions were noted. See Table 11 below.

Table 11

ANOVA

\begin{tabular}{|c|c|c|c|c|c|c|}
\hline Model & & Sum of Squares & $\mathrm{df}$ & Mean Square & $\mathrm{F}$ & Sig. \\
\hline \multirow[t]{3}{*}{1} & Regression & 174.028 & 2 & 87.014 & .867 & $.424^{\mathrm{b}}$ \\
\hline & Residual & 8225.972 & 82 & 100.317 & & \\
\hline & Total & 8400.000 & 84 & & & \\
\hline \multirow[t]{3}{*}{2} & Regression & 371.930 & 3 & 123.977 & 1.251 & $.297^{\mathrm{c}}$ \\
\hline & Residual & 8028.070 & 81 & 99.112 & & \\
\hline & Total & 8400.000 & 84 & & & \\
\hline
\end{tabular}

a.Dependent Variable: Compassion Satisfaction

b.Predictors: Years of Experience, Gender

c.Predictors: Years of Experience, Gender, Frequency of Contact 


\section{Chapter 4}

\section{Discussion}

This study revealed some interesting and important results. Both descriptive and regression results depicted a sample of clinicians who appeared generally resilient and compassion satisfied despite their arduous work environment and exposures to difficult clients. The frequency of contact (FOC) variable, or number of clients on a caseload admitted to inpatient care due suicidal gestures, was found to be an insignificant predictor within regression analysis. However, decreasing resiliency was found to predict increased burnout, and increased resiliency was found to predict increased compassion satisfaction in significant ways among the sample population. These significant findings are discussed below.

The Professional Quality of Life Scale (ProQOL) Version 5 was used to define the criterion variables in all multiple regression analyses. Four multiple regression analyses were conducted in total, and all participants were drawn from the same sample $(n=85)$ of inpatient clinicians providing services in the United States at acute/crisis facilities. The ProQOL is a 30item self-report measure that is commonly used to assess the levels of BO, STS, and CS. The Resiliency Scale 14 (RS-14), which is a 14-item measure, was used to define the predictor variable of resiliency among inpatient practitioners. This instrument was selected because it was hypothesized that varying levels of clinician resiliency would impact the predictive line in regards to the degree of observed changes in the criterion variables (BO, STS, CS). It was also hypothesized that increased measured resiliency would be associated with increased scores on the CS subscale. This would be a logical finding considering CS may be associated with better work adjustment, suggesting more adaptable levels of resiliency.

Frequency of contact (FOC) was also selected as a predictor variable and was defined as the number of clients on an inpatient caseload that were admitted to a clinician's inpatient care 
due to suicidal behaviors. The FOC variable was developed specifically for this study and was based on a dose-effect hypothesis. Through viewing suicidal behaviors as potentially traumatizing occurrences, it was logical to assume that those exposed to a higher frequency of contacts with suicidal presentations would demonstrate decreased CS and increased BO and STS with these relationships being dependent on the individual clinician's resiliency level. Past research findings have shown that the development of secondary traumatic stress/compassion fatigue and burnout appear to be related to prolonged and frequent exposure to clinical situations that are stressful and potentially vicariously traumatizing (Cornille \& Meyers, 1999; Rich, 1997; Shah et al., 2007; Wee \& Myers, 2002). Moreover, research on working with suicidal clients has consistently demonstrated that clinicians rate this kind of clinical activity as being extremely taxing and stressful (Menninger, 1991).

Summarizing the first three hypotheses into a single concept, it was hypothesized that clinicians who demonstrated lower levels of measured resiliency and who were exposed to higher frequencies of contact with suicidal presentations on their caseload would be more likely to demonstrate increased BO and STS and would be less likely to experience CS. The fourth multiple regression analysis included gender, years of experience, and frequency of contact as predictors. Within the model, these variables were entered hierarchically with CS subscale scores identified as the criterion variable. The conceptual design of the fourth multiple regression analysis was based on the observation that compassion satisfaction is an outcome opposite of either BO or STS (Stamm, 2010). Furthermore, gender has been found to be an important predictor of STS and compassion fatigue in previous research (Sprang et al., 2007). Fewer years of experience has also been shown to be predictive and associated with the onset of 
both BO and compassion fatigue (Badger et al., 2008; Craig \& Sprang, 2010, Ghahramanlou \& Brodbeck, 2000).

\section{Descriptive Results}

Descriptive results revealed that $18.8 \%$ of the sample (16 participants) scored in the high range (scores greater than 57) on the Burnout subscale of the ProQOL Version 5. The majority of the sample scored in the average range (81.2\%). However and interestingly, no participants scored in low the range on this subscale. Even though this finding is only descriptive in nature, it suggests that a significant proportion of the sample, nearly $20 \%$, responded to survey items in ways that suggest that they experience high levels of burnout secondary to their work within an inpatient treatment facility. These results did not consider the impact of suicidal presentations specifically and simply provided a snapshot of the prevalence of burnout among inpatient clinicians who completed survey materials. Stamm (2010), the author of the ProQOL instrument reported that those who score in these ranges (high) are at risk to experience the effects of burnout.

Descriptive results from the secondary traumatic stress (STS) subscale showed similar findings. STS has been conceptualized as the second aspect of the compassion fatigue construct occurring alongside of burnout (Stamm, 2010). People who score in high ranges on the STS scale may experience difficulties sleeping, may be generally fearful, and sometimes experience intrusive and unsettling thoughts that serve as reminders of a particular traumatic event (Stamm, 2010). The results indicated that approximately $22 \%$, or 19 of the 85 participants, scored in the high range on the secondary traumatic stress subscale and 19 participants (22\%) scored in low range with 47 participants scoring in the average range. Again, this finding is only descriptive in nature and does not consider the impact of exposures to suicidal behaviors. Yet, a significant 
proportion of the sample responded to survey items in ways that suggest that their work in inpatient facilities can be damaging on psychological and emotional levels.

Compassion fatigue was defined in the literature review as the collective influence of both burnout and secondary traumatic stress. Because a sizeable proportion of participants in this study scored in the high ranges for both the STS (22\%) and BO (18.8\%) subscales of the ProQOL Version 5, it is logical to assume that working in the inpatient setting may in fact be a risk factor for the development of compassion fatigue for some. Other studies have corroborated this result. For example, Sprang et al. (2007) found that inpatient professionals reported significantly higher burnout scores when compared to private practice professionals; the authors also found that $13 \%(n=1,121)$ of all clinicians (both inpatient and outpatient settings) included in data analysis scored in the high-risk range for compassion fatigue and burnout.

On the compassion satisfaction subscale, approximately $28.2 \%(n=24)$ of the participants scored in the high range, $16.5 \%(n=14)$ of the sample scored in the low range, and $55.3 \%(n=47)$ of the sample scored in the average range. On this scale, low scores are suggestive of impaired job satisfaction and indicate that an individual is at risk to experience problems at work (Stamm, 2010). The $16.5 \%$ of participants who scored in the low range on this scale were similar to the high scores reported on BO (18.8\%) and STS (22.4\%) subscales. These descriptive findings provide evidence that those who experience secondary traumatic stress and burnout are less likely to experience compassion satisfaction.

Nonetheless, it is important to note that the majority of the sample scored in the average $(55.3 \%)$ or high $(28.2 \%)$ ranges of this scale suggesting that cumulatively, $83.5 \%$ of the sample finds satisfaction with their employment in inpatient facilities. This finding may be an artifact of the characteristics of the sample. For example, those who experienced very low levels of 
compassion satisfaction may have left the inpatient setting as their place of employment or didn't respond to the survey. It is also possible that the clinicians who generally experienced more intact resiliency levels may have been more likely to complete the survey materials.

Descriptive results from the Resiliency Scale-14 also showed the average score across the sample to be 83.61 and approximately $88.2 \%$ of the sample scored in the moderate to high ranges of resiliency. This is a favorable result, suggesting that the majority of clinicians included in this study experience healthy levels of resiliency. Interestingly, the high levels of resiliency largely mirrored the high levels of compassion satisfaction (83.5\%) across the sample, which suggested that the two constructs might be related. Approximately $11.8 \%$ of the sample scored in the low to very low ranges of resiliency.

\section{Professional Quality of Life}

Stamm (2010) provided an interpretation guide for ProQOL in the manual. She reported that high levels of compassion satisfaction and moderate to low levels of burnout and secondary traumatic stress are the most favorable result, indicating a favorable professional quality of life. The results of this study indicated that $81.2 \%$ of the sample scored in the average range on the burnout scale and $28.2 \%$ scored in the high range of compassion satisfaction subscale. These findings were consistent with the generally high levels of resiliency encountered across the sample. Interestingly, the greater percentages of high scorers were on the secondary-traumatic stress scale (22.4\% high scores) and compassion satisfaction scale (28.2\% high scores). Stamm (2010) reported that this combination "is typically unique to high-risk situations such as working in areas of war and civil violence" (p. 23) and is often seen among people who feel their work is very important and matters (Stamm, 2010). This mirrors the inpatient acute/crisis setting, as it 
can be a stressful place to work and the services provided are crucial, especially when considering suicide.

\section{Hypotheses}

Hypothesis one predicted that high frequencies of contact (FOC) with suicidal clients and low levels of resiliency would be associated with increased scores on the burnout subscale of the ProQOL Version-5. This analysis revealed partially significant results. The FOC and measured resiliency level were entered into the regression model as predictors in a standard fashion with Burnout subscale scores entered into the model as a criterion variable. The results of the analysis showed that lower levels of resiliency appeared to significantly predict burnout scores, as the $b$ value was negative and with medium effect size, with $27 \%$ of the variance accounted for in this model. However, the FOC variable did not predict burnout scores in a significant way. These findings provided important empirical support to the anecdotal observation that resiliency level and experienced burnout are significantly related among inpatient clinicians working within acute care inpatient crisis facilities. Furthermore, the implications of this result suggest that clinicians with lower levels of resiliency may be more prone to experience burnout in this clinical setting.

Hypothesis two predicted that increased FOC with suicidal clients and low levels of resiliency would be associated with increased scores on the Secondary Traumatic Stress subscale of the ProQOL Version-5. The FOC and resiliency variables were entered into the model as predictors in a standard fashion. STS scores were entered into the model as the sole criterion variable. The result of this analysis was not significant, and this finding was contrary to the expected results. It was believed that higher frequencies of contact to suicidal presentations would increase the likelihood of vicarious traumatization among clinicians; however, the FOC 
variable did not account for a significant amount of the variance. Yet, it is likely that exposures to difficult client narratives including tales of suicidal behaviors can be vicariously traumatizing. However, within this study the content and scope of what was communicated in sessions from client to clinician was not considered. Thus, it was possible that transmission of traumatic stress from client to clinician was minimized by little specific discussion of the actual suicidal behaviors in therapy sessions. These results also suggest that resiliency level might play less of a part in the onset of STS than in BO. Why might this be the case? Again, and similar to why the FOC variable did not impact the variance in a significant way, it may be that the components of the FOC variable were not powerful enough to transmit traumatization in ways specifically linked to suicidal presentations.

Hypothesis three predicted that fewer frequencies of contact with suicidal clients and high levels of resiliency would be associated with favorable scores on the Compassion Satisfaction (CS) subscale of the ProQOL Version-5. For this analysis, scores on the CS subscale were selected as the primary criterion variable. Two predictor variables were identified, FOC and resiliency level. This hypothesis was tested through multiple regression analysis with the identified predictors entered into the model in a standard fashion. The results demonstrated partially significant results similar to the results encountered in hypothesis one. More specifically, it was found that increased levels of resiliency significantly predicted CS scores with medium effect, as $24 \%$ of the variance was accounted for in this model. These findings again provided empirical support to the notion that increased resiliency may be associated with more positive work experiences (CS) rather than negative work experiences (BO, STS) among inpatient clinicians. However, and again similar to hypothesis one, FOC was not found to be a significant predictor of the level of CS. 
Hypothesis four predicted that female gender, fewer years of clinical experience, and higher frequencies of contact with clients admitted to care due to suicidal behaviors would be associated with decreased scores on the CS subscale. For this analysis, the CS subscale was selected as the primary criterion variable because an absence of compassion satisfaction is suggestive of increased levels of both secondary traumatic stress and burnout (Stamm, 2010). A multiple linear regression analysis was conducted to predict CS subscale scores. Gender, years of experience, and frequency of contact (FOC) were entered into the model hierarchically in the order above. This model did not significantly predict CS. This was a surprising finding, given previous research results that have indicated gender and fewer of years of experience to be risk factors among helpers who work with trauma (Sprang et al., 2007).

When developing this study, it was logical to assume that higher contacts with suicidal presentations would lead to increased burnout, secondary traumatic stress, and decreased compassion satisfaction among inpatient clinicians. Extant research supported this assumption. For example, past findings demonstrated that clinical work with difficult case presentations and frontline exposures to trauma can increase the likelihood of an individual developing compassion fatigue, secondary traumatic stress, and even burnout (Cornille \& Meyers, 1999; Shah et al., 2007; Wee \& Myers, 2002). With this logic and previous research in favor of the posited hypothesis, the study moved forward and the frequency of contact (FOC) variable was created.

However, the results of four multiple regressions failed to identify the FOC variable as a significant predictor of burnout, secondary-traumatic stress, or low levels of compassion satisfaction. This finding was contrary to what was expected, and this finding may have been an artifact of a third variable problem. For example, an inpatient clinician's day is likely filled with other activities that are stressful beyond contact with suicidal presentations (paperwork, high 
pathology, client turnover). With this being the case, it was likely difficult to determine the impact of a single variable (FOC) over the noise of many potential confounding variables, and this may explain why the FOC variable was found to be an insignificant predictor.

Another potential explanation of why the FOC variable was not found to be significant with either the burnout or secondary traumatic stress constructs may have been associated with the high client turnover rates inherent to inpatient treatment settings. Figley (2002) suggested that empathic engagement could be the primary vehicle of traumatic stress from clients to clinicians. However, is there enough time for clinicians to develop therapeutic relationships that could potentially put them at risk to develop the adverse effects of helping within the acute inpatient settings? This is an empirical question that needs further analysis.

These results provide important information especially regarding the relationship between resiliency level and the professional quality of life construct. More specifically, the results appear to suggest that high levels of resiliency are more often associated with more favorable outcomes such as compassion satisfaction and low levels of resiliency appear to predict burnout scores. This outcome may be related to the notions of adaptability and flexibility in the face of adversity. For instance, those who demonstrate higher levels of resiliency may be better equipped to handle multiple difficult demands, both clinical and organizational. While those with lower levels of resiliency may be less equipped to manage these demands, leading to the emergence of burnout. Raquepaw and Miller (1989) found that clinicians who commonly felt overwhelmed generally scored higher on the Depersonalization subscale of the Maslach Burnout Inventory. The authors also found that perceptions of efficacy and effective coping appear to be important protective factors in averting burnout (Raquepaw \& Miller, 1989). In summary, these 
significant results may be explained by the proposition that increased resiliency is associated with higher levels of adaptability, flexibility, and coping.

Rutter (2007) suggested that resilience cannot exist without the presence of adversity, and a concise definition of resiliency describes the construct as an ability to bounce back from adversity. For inpatient clinicians, adversity is certainly present on a daily basis, manifested in the form of difficult clients, potentially vicariously traumatizing situations, piles of paperwork, and a rapid paced high stress work environment. The results of this study suggested that this sample of inpatient clinicians may be a resilient group as the majority $(88.2 \%)$ scored in the moderate high range on the RS-14. This was a logical finding, as those who were less resilient would be unlikely to continue a career in this difficult work setting. In fact, the average number of years employed in the setting across the sample was just over 11 years.

Kolar (2011) suggested that research that adopts a process view of the resiliency construct allows for a focus on the holistic interplay of factors. Kolar (2011) stated "a processbased understanding facilitates the evaluation of resilience as a shared responsibility between individuals, their families, and the formal social system rather than as an individual burden" (p. 425). Through adopting the theoretical position of resiliency as a process related construct, the findings of this research illustrate the interplay between intact resiliency levels and the emergence of compassion satisfaction among inpatient clinicians working in crisis settings.

\section{Strengths}

This study represented an attempt to determine how clinical work with suicide in inpatient settings may impact the professional quality of life when considering resiliency level. This was the first known study to attempt to empirically describe those potential relationships. The sample included 85 male and female licensed practitioners operating at acute/crisis centers 
across the United States. A particular strength of this study was survey-based design. Even though there are certain limitations associated this kind of research methodology, this study was effective in gathering real world data that described the professional quality of life and resiliency levels of an active sample of clinicians providing important clinical services to a high risk population of consumers. The knowledge gained through this research provides the foundation for further investigations of the relationships between resiliency levels, burnout, and compassion satisfaction among inpatient clinicians.

An important finding suggested that resiliency may be a protective factor against the development of burnout and may even promote the onset of compassion satisfaction. A larger more controlled study is needed to corroborate these findings. Yet, it has long been known on an anecdotal level that those who are more resilient may have more favorable vocational experiences in general and be more likely to stay with a difficult but important helping profession (Stamm, 2010). These results provided further empirical support to this position.

Surprisingly and contrary to the hypotheses, higher frequencies of contact with clients admitted to care due to suicidal behaviors did not significantly predict increased burnout or secondary traumatic stress scores. Even though not statistically significant, this result is extremely important. For example, it is possible that the short time durations of treatment common in acute/crisis units may not sufficiently allow for a strong therapeutic relationship to develop between clinician and client. Is it possible that the short time durations of treatment may actually be a protective factor for inpatient clinicians? This warrants further exploration.

Cunningham (2003) suggested that future studies of vicarious traumatization or compassion fatigue should include investigation of clinician personality factors that may serve as either agonist or antagonist to the development of the negative effects of helping. The results of 
this study showed clinician resiliency to be an important protective factor against one aspect of the compassion fatigue construct (burnout). The results also indicated that intact resiliency may also be one potential ingredient associated with the onset of compassion satisfaction. A major strength of this study was associated with the fact this research project successfully measured the adaptive functions of resiliency among a specific population of mental health workers and provided support for the adaptive benefits of the construct in a high stress clinical environment.

Luthar (2006) proposed that the core aspect of the resiliency construct is its tendency to emerge when in difficult circumstances and environments. The results of this study found that the inpatient clinician population, or those who were willing to complete the survey materials, appeared to be a generally resilient group. Regardless of a possible selection bias, it was found that increased resiliency level predicted decreased burnout level and increased compassion satisfaction.

\section{Limitations}

This study examined the professional quality of life and resiliency of a sample of active clinicians who provided psychotherapeutic services to adult populations within acute/crisis inpatient treatment settings. The results of four multiple regression analyses revealed some important findings. For example, it was found that increased clinician resiliency levels appeared to be associated with lower levels of burnout. Additionally, it was found that increased resiliency levels appeared associated with higher levels of compassion satisfaction. These significant findings provided empirical support to the notion that intact resiliency is associated with more favorable outcomes among this sample of inpatient clinicians.

As important as these findings may be, it is important to note some potential limitations of this study. Most broadly, this study implemented a survey based ex-post facto descriptive 
design. The approach was chosen because the constructs of interest were naturally occurring within the context of counseling and therapy with suicidal clients in crisis stabilization settings. This approach enabled the researcher to collect real world data regarding the professional quality of life of inpatient practitioners. However, it is important to note that the results produced from survey-based research can sometimes be impacted by various sources of uncontrolled noise.

There were many potential third variables within this design, which may be a significant limitation. For example, participants were not recruited from a single acute/crisis inpatient setting; they were recruited from a range of private, public, non-profit, and for-profit inpatient treatment facilities across the United States. Even though this spread may have added to the generalizability of the significant results, it may have also added sources of bias and error as well. For example, the policies and procedures, the professional milieu, and client populations may have differed from facility to facility. This was an unavoidable limitation.

A selection bias may have also been a limitation of this study. For example, would overly burned out or compassion fatigued inpatient clinicians bother to complete the survey? Data collection was difficult and a drawn out process. It was difficult to entice participants to complete the survey and it was certainly possible that those with more intact professional quality of lives or those who worked in more favorable environments were generally more prone to complete the survey materials. In fact, descriptive results from the Resiliency Scale 14 showed that $88.2 \%$ of the sample scored in the moderate to high ranges of resiliency. Therefore, it was difficult to conclude whether or not the sample was a resilient group or whether more resilient clinicians self-selected into the data analysis pool.

A lack of a comparison or control group was also a potential limitation. A control group could have added to the specificity of the statistical tests, providing a point of comparison, and 
allowing more accurate inferences to be made. However, the formation of a control group would have added to the sample size and added to the complexity of an already logistically difficult study.

The measures included in the data analysis demonstrated adequate psychometric properties but there had been some conceptual debate about the constructs included. Nonetheless, Cronbach's alpha scores were found to be in acceptable levels for all the included variables. However, a potential limitation of the ProQOL Version-5 was associated with the fact that the measure does not compute a composite score that can be used to describe the professional quality of life construct entirely. Instead, interpretation is based on some subjectivity. For example, combinations of the constructs that comprise the ProQOL are used to describe the professional quality of life informed by the obtained scores that are converted to tscores. Within the manual, the interpretative combinations are generally most weighted on high and low score combinations of the subscales. For example, the most favorable score combination is high compassion satisfaction and low burnout and secondary traumatic stress. These scoring guides are not as effective and illustrative when the majority of a sample scores in the average range on three subscales.

\section{Conclusions and Future Directions}

Clinical work with suicidal clients is a daily activity for inpatient therapists. Yet, the topic has been somewhat ignored within the general trauma literature. This study filled an important gap and facilitated the development of some important future research questions in the area. Suicide will continue to be an ongoing public and mental health concern, and the psychological after-effects of the phenomenon will continue to impact both the families of the victims and those professionals who treat survivors on a daily basis within inpatient treatment settings. 
In 2007, the National Institute of Mental Health (NIMH) reported that suicide was the tenth leading cause of death in the United States; accounting for 34,598 lives (National Institute of Mental Health [NIMH], 2011). It has been estimated that 95 Americans take their life on a daily basis, and 2,370 may attempt (American Foundation for Suicide Prevention [AFSP], 2011). Mental illness has long been linked to increased risk for death by suicide and nearly $90 \%$ of people who commit suicide experienced significant mental health concerns (American Association of Suicidology [AAS], 2011).

Nearly one fourth of all mental health clinicians will experience the death of a client due to suicide (McAdams \& Foster, 2000). The rate is certainly higher for clinicians working in inpatient settings with regular exposures to caseloads filled with individuals admitted to care due to suicidal behavior. Pope and Tabachnick (1993) identified the prospect of client suicide as being one of the greatest fears helpers face. Other research has shown that when clinicians experience the death of a client by suicide, their confidence as agents of change is shaken and negative emotionality directed towards the helping process and the mental health system can emerge (Richards, 2000).

This study applied Stamm's (2010) professional quality of life construct (ProQOL) to the daily lives of inpatient clinicians working in acute/crisis inpatient settings. Resiliency levels along with the constructs measured within the ProQOL (burnout, secondary traumatic stress, and compassion satisfaction) were specifically examined. The results of this study showed that the frequency of contact with suicidal presentations within the inpatient setting did not predict increasing levels of burnout and secondary traumatic stress and decreasing levels of compassion satisfaction. However, the results showed that low levels of resiliency appeared to significantly predict increased levels of burnout among inpatient clinicians. Additionally, it was found that 
high levels of resiliency significantly predicted higher levels of compassion satisfaction among inpatient clinicians. This finding in particular may be suggestive of the existence of a latent variable that combines characteristics of both resiliency and compassion satisfaction into a single construct. This study also showed that the average clinician who maintains employment in the inpatient crisis setting might be a more resilient individual in general.

The findings discussed above are important. However, the results of this research opened a few new questions that certainly warrant further investigation. Most importantly, why was the frequency of contact variable shown to be ineffective in facilitating higher levels of burnout or secondary traumatic stress among inpatient clinicians? This is an empirical question, but the design and findings of this research hint at some potential explanations. For example, this study did not specifically assess the content of what was communicated between clients and therapists following admission to the units during therapy sessions. How were the behaviors described? Were the behaviors minimized or embellished? Additionally, the particulars of the suicide attempt were not examined in this study as well. Considering these observations, future research regarding the frequency of contact with suicidal clients needs to consider the particulars of the event and how the event is communicated in therapy sessions. It is likely that the transmission of traumatic stress is dependent on these factors.

In conclusion, the results of this study showed that this particular sample of inpatient clinicians appeared to be a resilient group despite their work environment. Though this finding was contrary to what was expected it is nonetheless encouraging, suggesting that intact resiliency can serve as a protective factor in difficult clinical work environments. These results also provided empirical support to the notion that resiliency, burnout, and compassion satisfaction are significantly intertwined. Most importantly, this study opened a new line of research focused on 
understanding the psychological tolls associated with the delivery of counseling services to recent survivors of suicide attempts while also examining the inherent strength, resiliency, and adaptability of those clinicians who choose to provide these important services. 


\section{References}

American Academy of Child \& Adolescent Psychiatry (2011). Retrieved from www.aacap.org/ publications/factsfam/continum.html

American Psychiatric Association. (2013). Diagnostic and statistical manual of mental disorders (5th ed.). Washington, DC: Author.

American Association for Suicide Prevention (2011, October 11). Retrieved from http://www.afsp.org/index.cfm?page_id=04EA1254-BD31-1FA3-C549D77E6CA6AA37

American Association of Suicidology (2011, October 11). Retrieved from http://www.suicidology.org/web/guest/stats-and-tools/fact-sheets

Adams, C. L., \& El-Mallakh, R. S. (2009). Patient outcome after treatment in a communitybased crisis stabilization unit. Journal of Behavioral Health Services \& Research, 36(3), 396-399. doi:10.1007/s11414-008-9141-3

Badger, K., Royse, D., \& Craig, C. (2008). Hospital social workers and indirect trauma exposure: an exploratory study of contributing factors. Health \& Social Work, 33(1), $63-71$.

Baird, K., \& Kracen, A. C. (2006). Vicarious traumatization and secondary traumatic stress: A research synthesis. Counselling Psychology Quarterly, 19(2), 181-188

Balkin, R. S. (2006). A reexamination of trends in acute care psychiatric hospitalization for adolescents: ethnicity, payment, and length of stay. Journal of Professional Counseling: Practice, Theory \& Research, 34(1/2), 49-59.

Block, J. H., \& Block, J. (1980). The role of ego-control and ego-resiliency in the organization of behavior. In W. A. Collins (Ed.). Development of cognition, affect, and social relations: The Minnesota symposia on child psychology (Vol. 13). Hillsdale, NJ: Erlbaum. 
Bradley, R., Heim, A., \& Westen, D. (2005). Transference patterns in the psychotherapy of personality disorders: Empirical investigation. British Journal of Psychiatry, 186, 342349. doi:10.1192/bjp.186.4.342

Bride, B. E. (2004). The impact of providing psychosocial services to traumatized populations. Stress, Trauma, and Crisis, 7, 29-46.

Britton, P. C., Williams, G. C., \& Conner, K. R. (2008). Self-determination theory, motivational interviewing, and the treatment of clients with acute suicidal ideation. Journal of Clinical Psychology, 64(1), 52-66. doi:10.1002/jclp.20430

Centers for Disease Control and Prevention (2013, January 12). Web-based Injury Statistics Query and Reporting System (WISQARS) [online] [Website]. Retrieved from www.cdc.gov/injury/wisqars/index.html.

Chemtob, C. M., Hamada, R. S., Bauer, G., Torigoe, R. Y., \& Kinney, B. (1988). Patient suicide: Frequency and impact on psychologists. Professional Psychology: Research and Practice, 19(4), 416-420. doi:10.1037/0735-7028.19.4.416

Clarke, D., \& Winsor, J. (2010). Perceptions and needs of parents during a young adult's first psychiatric hospitalization: "we're all on this little island and we're going to drown real soon". Issues in Mental Health Nursing, 31(4), 242-247. doi: $10.3109 / 01612840903383992$

Cohen, J. (1992). A power primer. Psychological Bulletin, 112(1), 155-159.

Cornille, T.A., \& Meyers, T.W. (1999). Secondary traumatic stress among child protective service workers: Prevalence, severity and predictive factors. Traumatology, 5, 15-31. 
Craig, C. D., \& Sprang, G. G. (2010). Compassion satisfaction, compassion fatigue, and burnout in a national sample of trauma treatment therapists. Anxiety, Stress \& Coping, 23(3), 319-339. doi:10.1080/10615800903085818

Cunningham, M. (2003). Impact of trauma work on social work clinicians: Empirical findings. Social Work, 48, 451-459.

Edward, K. (2005). The phenomenon of resilience in crisis care mental health clinicians. International Journal of Mental Health Nursing, 14(2), 142-148. doi:10.1111/j.14400979.2005.00371.x

Elkins, D. N. (2012). Toward a common focus in psychotherapy research. Psychotherapy, 49(4), 450-454. doi:10.1037/a0027797

Erdfelder, E., Faul, F., \& Buchner, A. (1996). GPOWER: A general power analysis program. Behavior Research Methods, Instruments, \& Computers, 28, 1-11

Farber, B. (1990). Burnout in psychotherapists: Incidence, types, and trends. Psychotherapy in Private practice, 8(1), 35-44.

Field, A. (2009). Discovering statistics using SPSS, $3^{\text {rd }}$ Edition. London: Sage Publications.

Flückiger, C., Del Re, A. C., Wampold, B. E., Symonds, D., \& Horvath, A. O. (2012). How Central Is the Alliance in Psychotherapy? A Multilevel Longitudinal MetaAnalysis. Journal Of Counseling Psychology, 59(1), 10-17.

Follette, V., Polusny, M., \& Millbeck, K. (1994). Mental health and law enforcement professionals: Trauma history, psychological symptoms, and impact of providing services 
to child sexual abuse survivors. Professional Psychology, Research and Practice, 25, 275282.

Fothergill, A., Edwards, D., \& Burnard, P. (2004). Stress, burnout, coping, and stress management in psychiatrists: Findings from a systematic review. International Fox, R.J.,Crask, M.R., \& Kim, J. (1988). Mail survey response rate: A meta-analysis of selected techniques for inducing response. Public Opinion Quarter, 52, 467-491. Journal of Social Psychiatry, 50, 54-65.

Figley, C. R. (1995). Compassion fatigue: Coping with secondary traumatic stress disorder in those who treat the traumatized. Levittown, PA: Brunner/Mazel.

Figley, C. R. (2002). Compassion fatigue: Psychotherapist's chronic lack of self-care. Journal of Clinical Psychology in Session: Psychotherapy in Practice, 58(11), $1433-1441$.

Figley, C.R., \& Stamm, B.H. (1996). Psychometric review of compassion fatigue self-test. In B.H. Stamm (Ed.), Measurement of stress, trauma and adaptation. Lutherville, MD: Sidran Press.

Freudenberger, H. (1974). Staff burn-out. Journal of Social Issues, 30(1), 159-165.

Freudenberger, H. J. (1985). Women's burnout: How to spot it, how to reverse it, and how to prevent it. Garden City, NY: Doubleday.

Gelso, C. J., \& Bhatia, A. (2012). Crossing theoretical lines: the role and effect of transference in nonanalytic psychotherapies. Psychotherapy, 49(3), 384-390. doi:10.1037/a0028802

Goodman, G. (2005). "I Feel Stupid and Contagious:" Countertransference reactions of fledgling clinicians to patients who have negative therapeutic reactions. American Journal of Psychotherapy, 59(2), 149-168. 
Ghahramanlou, M., \& Brodbeck, C. (2000). Predictors of secondary trauma in sexual assault trauma counselors. International Journal of Emergency Mental Health, 2, 229-240.

Heppner, P.,Wampold, B.E., Kivlighan, D.M., (2008). Research design in counseling. Belmont, CA: Thompson Brooks/Cole.

Hummelvoll, J.K.\& Severinsson, E. (2001). Coping with everyday reality: mental health professionals' reflections on the care provided in an acute psychiatric ward. The Australian and New Zealand Journal of Mental Health Nursing, 10(3), 156-166.

Jacobs, D., \& Brewer, M. (2004). APA practice guideline provides recommendations for assessing and treating patients with suicidal behaviors. Psychiatric Annals, 34(5), 373380.

Jenkins, S.R., \& Baird, S. (2002). Secondary traumatic stress and vicarious trauma: A validational study. Journal of Traumatic Stress, 15, 423-432

Kolar, K. (2011). Resilience: Revisiting the concept and its utility for social research. International Journal of Mental Health and Addiction, 9(4), 421-433. doi:10.1007/s11469-011-9329-2

Kruskal, W., \& Mosteller, F. (1979). Representative sampling, I: Nonscientific literature. International Statistical Review, 47, 13 (24).

Lawson, G., Venart, E., Hazier, R. J., \& Kottler, J. A. (2007). Toward a culture of counselor Wellness. The Journal of Humanistic Counseling, Education and Development, 46, 5-19. Lazarus, R.S., \& Folkman, S. (1984). Stress, appraisal, and coping. New York: Springer.

Lee, J., Lim, N., Yang, E., \& Lee, S. (2011). Antecedents and consequences of three dimensions of burnout in psychotherapists: A meta-analysis. Professional Psychology: Research And Practice, 42(3), 252-258. doi:10.1037/a0023319 
Leiter, M. P., \& Harvie, P. L. (1996). Burnout among mental health workers: A review and a research agenda. International Journal of Social Psychiatry, 42(2), 90-101.

Lent, J., \& Schwartz, R. C. (2012). The Impact of Work Setting, Demographic Characteristics, and Personality Factors Related to Burnout Among Professional Counselors. Journal of Mental Health Counseling, 34(4), 355-372.

Lerias, D., \& Byre, M. K. (2003). Vicarious traumatization: Symptoms and predictors. Stress and Health, 19, 129-138

Linley, P.A., \& Joseph, S. (2007). Therapy work and therapists' positive and negative wellbeing. Journal of Social and Clinical Psychology, 26, 385-403.

Luthar, S. S. (2006). Resilience in development: A synthesis of research across five decades. In D. J. Cohen \& D. Cicchetti (Eds.), Developmental psychopathology: Risk, disorder, and adaptation (pp. 739-795). Hoboken, NJ: John Wiley \& Sons.

Menninger, W. (1991). Patient suicide and its impact on the psychotherapist. Bulletin of the Menninger Clinic, 55, 216-227.

Maslach, C. (1982). Burnout, the cost of caring. Englewood Cliffs, NJ: Prentice Hall.

Maslach, C. (1986). Burnout research in the social services: A critique. Journal of Social Service Research, 10, 95-105.

Maslach, C. \& Jackson, S. E. (1986). Maslach Burnout Inventory: Manual (2nd). Palo Alto, CA: Consulting Psychologists Press.

McAdams, C. \& Foster, V. (2000). "Client Suicide: Its Frequency and Impact on Counselors." Journal of Mental Health Counseling, 22(2). 107-121. 
Murphy, R. A., \& Halgin, R. P. (1995). Influences on the career choice of psychotherapists. Professional Psychology: Research and Practice, 26(4), 422-426. doi:10.1037/07357028.26 .4 .422

Musa, S. A., Hamid, A. A. (2008). Psychological problems among aid workers operating in Darfur. Social Behavior \& Personality: An International Journal, 36, 407-416.

National Institute of Mental Health (2011, November 16). Retrieved from National Institute of Mental Health Statistics, http://www.nimh.nih.gov/statistics/index.shtml

O'Hara, D. (2012). Editorial: Common factors of therapeutic change in counselling psychology. Counselling Psychology Review, 27(4), 3-6.

Ong, A. D., Bergeman, C. S., \& Boker, S. M. (2009). Resilience Comes of Age: Defining Features in Later Adulthood. Journal of Personality, 77(6), 1777-1804. doi:10.1111/j.1467-6494.2009.00600.x

Phillips, S.D, Burns, B.J., Edgar, E.R., Mueser, K.T., Linkins, K.W., Rosenheck, R.A., Drake, R.E., \& McDonel, E.C. (2001). Psychiatric Services., 52, 771-779. doi:10.1176/appi.ps.52.6.771

Pope, K.S., \& Tabachnick, B.G. (1993). Therapists' anger, hate, fear, and sexual feelings: National survey of therapist responses, client characteristics, critical events, formal complaints, and training. Professional Psychology: Research and Practice, 24(2), 142152.

Potter, P., Deshields, T., Divanbeigi, J., Berger, J., Cipriano, D., Norris, L., et al. (2010). Compassion fatigue and burnout. Clinical Jouirnal of Oncology Nursing, 14, E56-E62. Raquepaw, J. M., \& Miller, R. S. (1989). Psychotherapist burnout: A componential analysis. Professional Psychology: Research and Practice, 20, 32-36. 
Rich, K.D. (1997). Vicarious traumatization: A preliminary study. In S.B. Edmunds (Ed.), Impact: Working with sexual abusers (pp. 7588). Brandon, VT: Safer Society Press.

Richards, B. M. (2000). Impact upon therapy and the therapist when working with suicidal patients: some transference and countertransference aspects. British Journal of Guidance \& Counselling, 28(3), 325-37.

Rogers, C. R. (2007). The necessary and sufficient conditions of therapeutic personality change. Psychotherapy: Theory, Research, Practice, Training, 44(3), 240-248. doi:10.1037/00333204.44.3.240

Rossi, A., Cetrano, G., Pertile, R., Rabbi, L., Donisi, V., Grigoletti, L., \& . Amaddeo, F. (2012). Burnout, compassion fatigue, and compassion satisfaction among staff in communitybased mental health services. Psychiatry Research, doi:10.1016/j.psychres.2012.07.029

Rothschild, B., \& Rand, M. (2006). Help for the helper, self-care strategies for managing burnout and stress: The psychophysiology of compassion fatigue and vicarious trauma. New York: W. W. Norton.

Rutter, M. (2007) Resilience, competence, and coping. Child abuse and Neglect, March; 31(3), 205-209.

Sabin-Farrell, R., \& Turpin, G. (2003). Vicarious traumatization: implications for the mental health of health workers?. Clinical Psychology Review, 23(3), 449. doi:10.1016/S02727358(03)00030-8

Shah, S.A., Garland, E., \& Katz, C. (2007). Secondary traumatic stress: Prevalence in humanitarian aid workers in India. Traumatology, 13, 59. 70. 
Sprang, G., Clark, J. J., \& Whitt-Woosley, A. (2007). Compassion Fatigue, Compassion Satisfaction, and Burnout: Factors Impacting a Professional's Quality of Life. Journal of Loss \& Trauma, 12(3), 259-280. doi:10.1080/15325020701238093

Stamm, B. H. (2002). Measuring compassion satisfaction as well as fatigue: Developmental history of the compassion fatigue and satisfaction test. In C. R. Figley (Ed.), Treating compassion fatigue (pp. 107-119). New York: Brunner-Routledge.

Stamm, B.H. (2005, January 7). The ProQOL Manuel. Institute of Rural Health, Idaho State University, Sidran Press. Retrieved from http://www.compassionfatigue.org/pages/ProQOLManualOct05.pdf

Stamm, B.H. (2010). The Concise ProQOL Manual, $2^{\text {nd }}$ Ed. Pocatello, ID: ProQOL.org.

Sørgaard, K, W., Ryan, P.,Hill., \& Dawson, I. (2007). Sources of stress and burnout in acute psychiatric care: inpatient vs. community staff. Social Psychiatry and Psychiatric Epidemiology, 42(10), 794-802.

Tabachnick, B. G., and Fidell, L. S. (2007). Using Multivariate Statistics , 6th ed. Boston: Allyn and Bacon.

Tugade, M.M., Fredickson, B.L., \& Barett, L.F. (2004). Psychological resilience and positive emotional granularity: examining the benefits of positive emotions on coping and health. Journal of Personality,72, 1161-1190. DOI: 10.1111/j.1467-6494.2004.00294.x

Wee, D., \& Meyers, D. (2002). Response of mental health workers following disaster: The Oklahoma city bombing. In C.R. Figley (Ed.), Treating compassion fatigue (pp. 57. 84). New York: Brunner/Routledge.

Wagnild, G.M \& Young H.M. (1990). Development among older women. Image: Journal of Nursing Scholarship, 22(4), 252-255. 
Wagnild, G.M \& Young H.M. (1993). Development and psychometric evaluation of the resilience scale. Journal of Nursing Measurement, 1, 165-178

Wagnild, G.M., \& Young. H.M. (2011). "The Resilience Scale" is an international trademark of Gail M. Wagnild \& Heather M. Young, 1993.

Wallsten, T., Kjellin, L., \& Lindström, L. (2006). Short-term outcome of inpatient psychiatric care-impact of coercion and treatment characteristics. Social Psychiatry \& Psychiatric Epidemiology, 4l(12), 975-980. doi:10.1007/s00127-006-0131-6

Wilczek-Rużyczka, E. (2011). Empathy vs. professional burnout in health care professionals. Journal of US-China Medical Science, 8(9), 526-532. 


\section{Appendix A: Professional Quality of Life Scale (ProQOL) Version 5}

When you help people you have direct contact with their lives. As you may have found, your compassion for those you help can affect you in positive and negative ways. Below are some questions about your experiences, both positive and negative, as a help. Consider each of the following questions about you and your current work situation. Select the number that honestly reflects how frequently you experienced these things in the last 30 days.

\section{$1=$ Never $2=$ Rarely $3=$ Sometimes $4=$ Often $5=$ Very Often}

1. I am happy.

2. I am preoccupied with more than one person I [help].

3. I get satisfaction from being able to [help] people.

4. I feel connected to others.

5. I jump or am startled by unexpected sounds.

6. I feel invigorated after working with those I [help].

7. I find it difficult to separate my personal life from my life as a [helper].

8. I am not as productive at work because I am losing sleep over traumatic experiences of a person I [help].

9. I think that I might have been affected by the traumatic stress of those I [help].

10. I feel trapped by my job as a [helper].

11. Because of my [helping], I have felt "on edge" about various things.

12. I like my work as a [helper].

13. I feel depressed because of the traumatic experiences of the people I [help].

14. I feel as though I am experiencing the trauma of someone I have [helped].

15. I have beliefs that sustain me.

16. I am pleased with how I am able to keep up with [helping] techniques and protocols.

17. I am the person I always wanted to be.

18. My work makes me feel satisfied.

19. I feel worn out because of my work as a [helper].

20. I have happy thoughts and feelings about those I [help] and how I could help them.

21. I feel overwhelmed because my case [work] load seems endless.

22. I believe I can make a difference through my work.

23. I avoid certain activities or situations because they remind me of frightening experiences of the people I [help].

24. I am proud of what I can do to [help].

25. As a result of my [helping], I have intrusive, frightening thoughts.

26. I feel "bogged down" by the system.

27. I have thoughts that I am a "success" as a [helper].

28. I can't recall important parts of my work with trauma victims.

29. I am a very caring person.

30. I am happy that I chose to do this work. 


\section{Appendix B: 14- Item Resiliency Scale}

How Resilient Are You?

Complete the Resilience Scale and find out. (or Take the RS-25)

*The highest level of education I have attained:

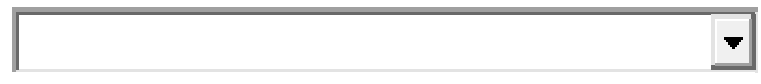

$$
\begin{aligned}
& \text { *My age: } \\
& \text { *My gender: Female Male } \\
& \text { The 14-Item Resilience Scale } \left.{ }^{\mathrm{TM}} \mathbf{( R S - 1 4}^{\mathrm{TM}}\right)
\end{aligned}
$$

\section{(Permission to use measure granted from author in February 2013)}

Please read the following statements. To the right of each you will find seven numbers, ranging from "1" (Strongly Disagree) on the left to "7" (Strongly Agree) on the right. Click the circle below the number which best indicates your feelings about that statement. For example, if you strongly disagree with a statement, click the circle below "1". If you are neutral, click "4", and if you strongly agree, click "7", etc. You must answer every question to submit the test for scoring.

1. I usually manage one way or another.

Strongly Strongly

Disagree Agree

$\begin{array}{lllllll}1 & 2 & 3 & 4 & 5 & 6 & 7\end{array}$

2. I feel proud that I have accomplished things in life.

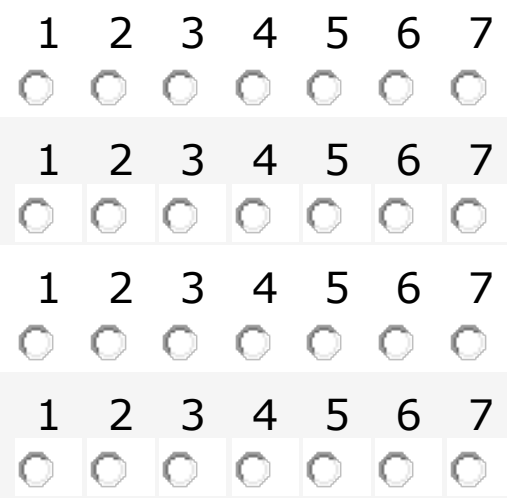

5. I feel that I can handle many things at a time.

6. I am determined.

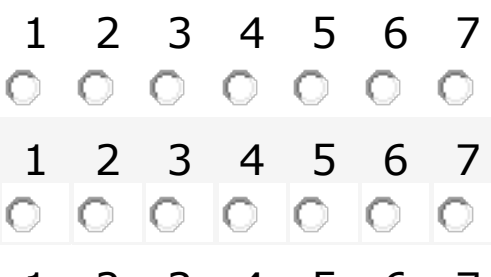

8. I have self-discipline.

$\begin{array}{lllllll}1 & 2 & 3 & 4 & 5 & 6 & 7\end{array}$ 
9. I keep interested in things.

$$
0000000
$$

$\begin{array}{lllllll}1 & 2 & 3 & 4 & 5 & 6 & 7\end{array}$

0000000

10. I can usually find something to laugh

$\begin{array}{lllllll}1 & 2 & 3 & 4 & 5 & 6 & 7\end{array}$ about.

11. My belief in myself gets me through hard times.

12. In an emergency, I'm someone people can generally rely on.

13. My life has meaning.

0000000

$\begin{array}{lllllll}1 & 2 & 3 & 4 & 5 & 6 & 7\end{array}$
0000000

$\begin{array}{lllllll}1 & 2 & 3 & 4 & 5 & 6 & 7\end{array}$

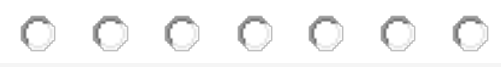

$\begin{array}{lllllll}1 & 2 & 3 & 4 & 5 & 6 & 7\end{array}$

000000

14. When I'm in a difficult situation, I can

$\begin{array}{lllllll}1 & 2 & 3 & 4 & 5 & 6 & 7\end{array}$ usually find my way out of it. 
Appendix C: Demographic Items

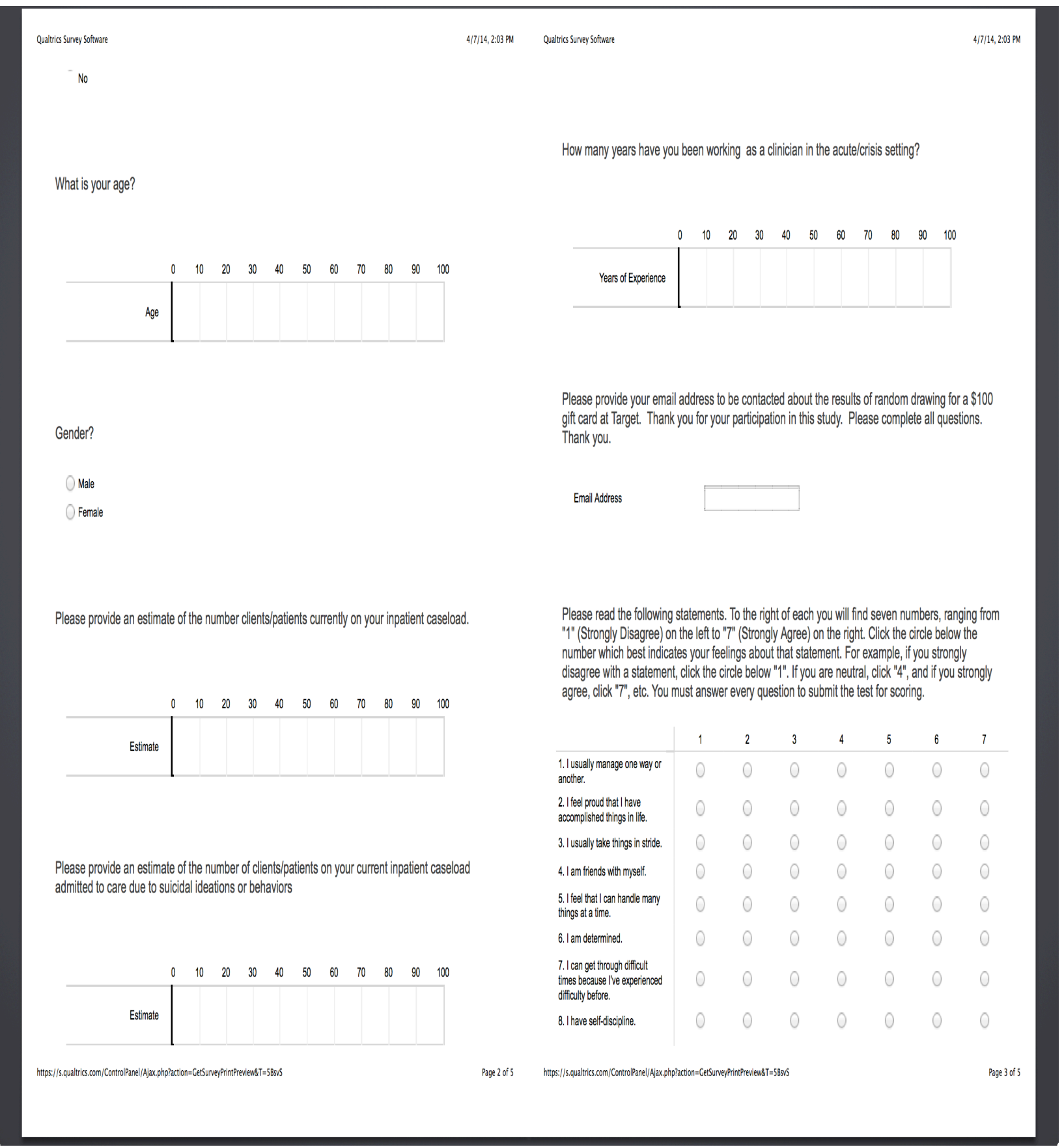




\section{Appendix D: Recruitment Email Script}

Dear Clinical Director (this will be personalized for each facility)

My name is William Little and I am a doctoral candidate at West Virginia University studying counseling psychology. I am contacting you because I am in the process of collecting data for my dissertation. I am working with my chair, Dr. Monica Leppma, PhD to study the impact that clinical work with suicidal clients in crisis settings has on licensed mental health practitioner's professional's quality of life. The title of my dissertation is The Professional Quality of Life and Resiliency in Mental Health Professionals Working with Suicide in Crisis Care. Within the professional quality of life construct exists the conditions known as secondary traumatic stress, burnout, and compassion satisfaction.

This study is strictly voluntary and you are by no means obligated to participate. The study does not entail any foreseeable risks to participants and has been approved by West Virginia University's Institutional Review Board (IRB). Additionally, all information will remain strictly confidential.

If you are interested in helping me collect data, please forward this email to licensed mental health professionals (LPC, MSW, LCSW, PhDs) who provide therapeutic services to adult clients within the inpatient crisis/acute setting at your facility. You are also welcome to complete the survey if you provide counseling services to adult clients who are admitted to inpatient care due to suicidal behaviors. You will find the link to my survey materials below. Everyone who completes my survey will be eligible to receive a 100 dollar gift card from Target once all data is collected. The winner of the gift card will be chosen at random.

If you have any questions about my study please do not hesitate to contact me at wlittle@mix.wvu.edu. You can also contact my chair, Dr. Monica Leppma at monica.leppma@mail.wvu.edu.

\section{Link to Survey Packet}

https:/qtrial.qualtrics.com/SE/?SID=SV_eD45zPv7riy4DmB

Thank you so much for your time and help!

Sincerely,

William Little 


\section{Appendix E: Informed Consent}

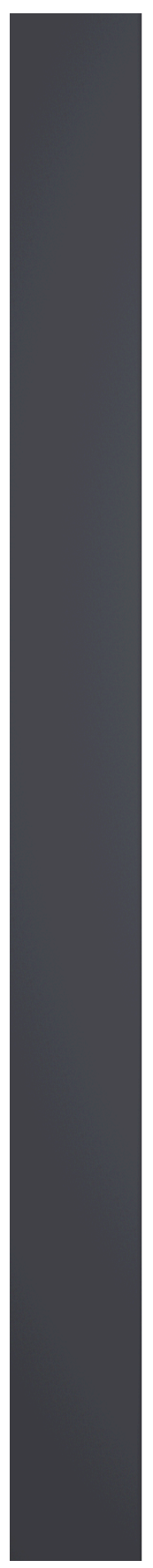

\section{Default Block}

\section{Dear Participant,}

This letter is a request for you to take part in a dissertation research project designed to assess how clinical work with adult clients admitted to inpatient psychiatric facilities due to suicidal gestures and clinician resiliency level impacts the professional quality of life. This project is being conducted by William Little, MS. Mr. Little is a doctoral candidate studying Counseling Psychology in the Department of Counseling, Rehabilitation Counseling, and Counseling Psychology at WU. This dissertation project is being supervised Dr.Monica Leppma. Dr. Leppma is an assistant professor in the College of Human Resources and Education. Your participation in this project is greatly appreciated and will take approximately 15 to 25 minutes to fill out the survey materials below.

Your involvement in this project will be kept as confidential as legally possible. All data will be reported in the aggregate. You must be 18 years of age or older to participate. I will not ask any information that should lead back to your identity as a participant. Your participation is completely voluntary. You may skip any question that you do not wish to answer and you may discontinue at any time. West Virginia University's Institutional Review Board acknowledgement of this project is on file.

I hope that you will participate in this research project, as it could be beneficial in understanding the impact of clinical work with suicide in the inpatient setting. Thank you very much for your time. Should you have any questions about this research project, please feel free to William Little (901) 832-6493 or by e-mail at wittle@mix.wvu.edu . You may also contact Dr. Leppma at(304) 2930540 or by email at Monica.Leppma@mail.wvu.edu.

Thank you for your time and help!

Sincerely, William Little 